\title{
AMPLIAÇÃO DO INVENTÁRIO DE EMISSÕES VEICULARES PARAA GESTÃO DOS TRANSPORTES NO ESTADO DE SÃO PAULO
}

\author{
Gabriel Murgel Branco ${ }^{\mathrm{a}}$ \\ Fábio Cardinale Branco ${ }^{\mathrm{b}}$ \\ Milton Xavier ${ }^{\mathrm{c}}$
}

\begin{abstract}
Resumo
Este trabalho complementa a elaboração do inventário de emissões veiculares tornando-o uma ferramenta útil para o planejamento e diagnóstico ambientaldos transportes que permita avaliar os benefícios ambientais advindos do seu reequilíbrio modal.

Foram incluídas inovações para refinar os resultados e ampliar o escopo incluindo poluentes ainda não regulamentados (aldeídos de motos e Diesel, etanol) e $\mathrm{GEE}\left(\mathrm{N}_{2} \mathrm{O}, \mathrm{CO}_{2}\right.$ e $\left.\mathrm{CH}_{4}\right)$, além dos modos ferro, hidro e aeroviário.

Foram incluídos fatores de deterioração reais, levantados por sensoriamento remoto, estimativas de frota baseadas nas curvas de sucateamento existentes, aferidas pelos dados do Programa I/M-SP, e curvas reais de quilometragem anual em função da idade obtidas no I/M-SP.

A inclusão de poluentes não regulamentados visa avaliar comparativamente sua importância, tanto para a poluição local como global, permitindo verificar a necessidade e oportunidade de estabelecer limites e metas de redução.

O inventário utiliza-se de dados brasileiros e, para os poluentes e modos de transporte para os quais não há informações nacionais disponíveis, de dados ou métodos de cálculo da bibliografia internacional.
\end{abstract}

Essa metodologia está sendo apresentada para abrir a discussão, visando o seu refinamento para posterior uso voltado ao planejamento estratégico dos transportes.

\section{EXTENDED VEHICLE EMISSIONS INVENTORY AS A TOOL FOR MANAGEMENT OF TRANSPORT}

\section{Abstract}

This paper improves and updates the vehicle emissions inventory making it an useful tool for transport planning and environmental diagnosis to evaluatethe benefits resulting from the reequilibrium of modal transport.

Innovations were included to refine the results and extend the scope including non regulated pollutants (aldehydes of motorcycles and Diesel, ethanol) and $\mathrm{GHG}\left(\mathrm{CO}_{2}, \mathrm{~N}_{2} \mathrm{O}\right.$ and $\left.\mathrm{CH}_{4}\right)$, in addition to the rail, hydro and aviation modes.

Actual deterioration factors were included in the calculation, estimated from remote sensing measurements, fleet estimates based on existing scrapping curves validated by the I/M Program data, and actual annual mileage curves as a function of age also obtained in I/M-SP.

The inclusion of non-regulated pollutants intends to evaluate their relative importance, both for local and global pollution, allowing to verify the need and opportunity to establish limits and reduction targets.

The inventory used the available Brazilian data for road vehicles, and international information and calculation methods for pollutants and transport modes from the bibliography.

This methodology is now presented to open the discussion of all premises and refinement for later use in the strategic transport planning.

\footnotetext{
${ }^{a}$ EnvironMentality - Consultor

${ }^{\mathrm{b} E n v i r o n M e n t a l i t y ~-~ C o n s u l t o r ~}$

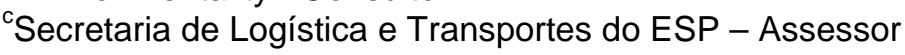




\section{Introdução}

O inventário é uma ferramenta de planejamento e diagnóstico ambiental das mais importantes por se prestar a estudos e projeções estatísticas de crescimento da emissão de poluentes que permitem uma avaliação das tendências de evolução do problema e o estabelecimento de estratégias que as modifiquem e sejamdimensionadas de maneira previsível e controlada.

Entretanto, os inventários oficiais existentes consideram somente as emissões regulamentadas para cada tipo de fonte, desprezando as demais, como por exemplo, a emissão de aldeídos dos motores a diesel ou a de material particulado dos motores Otto. Desta forma, eles destorcem a percentagem de contribuição de determinadas fontes e não servem para avaliar cenários onde seja estudada a inserção de modos específicos de transporte que ainda não tenham influência significativa no cenário ambiental.

Por esta razão, este inventário ainda preliminar foi ampliado, em moldes semelhantes aos que a EnvironMentality tinha proposto ao Ministério do Meio Ambiente em 2006, incluindoas emissões evaporativas devidas ao reabastecimento dos veículos,os modos de transporte ferro, hidro e aeroviário e expandido para considerar todos os poluentes em todos os tipos de veículo, sejam regulamentados ou não. Desta forma, foram considerados, para todos os tipos e idades de veículos, os fatores de emissão demonóxido de carbono (CO), óxidos de nitrogênio (NOx), material particulado (MP), hidrocarbonetos totais (THC), hidrocarbonetos não metânicos (NMHC), aldeídos, a correção da emissão de hidrocarbonetos $(\mathrm{HC})$ pelo cômputo da emissão de etanol (EtOH) nos veículos flex, as emissões evaporativas de etanol e de HC separadamente, emissão de $\mathrm{HC}$ pelo cárter para todos os veículos, bem como dos gases de efeito estufa dióxido de carbono $\left(\mathrm{CO}_{2}\right)$ fóssil e renovável,óxido nitroso $\left(\mathrm{N}_{2} \mathrm{O}\right)$, amônia $\left(\mathrm{NH}_{3}\right)$ e metano $\left(\mathrm{CH}_{4}\right)$.

Outra inovação introduzida neste inventário é a conversão das emissões de compostos orgânicos no "potencial de formação de ozônio", convertendo-os em "HC equivalente" numa mesma base de comparação dos seus efeitos sobre as reações fotoquímicas atmosféricas. Além disso, foram atualizados os valores de quilometragem anual e da percentagem da frota em desconformidade com 0 PROCONVE, extraídos das estatísticas do Programa de Inspeção e Manutenção do município de São Paulo - I/M-SP ${ }^{1}$, bem como fatores de deterioração de emissões de veículos leves determinados por sensoriamento remoto.

Os resultados deste inventário refletem a situação do ano base 2011 no Estado de São Paulo, para a qual existiam as estatísticas mais representativas da realidade no momento da sua elaboração. São ainda preliminares porque os métodos e dados disponíveis possuem diferentes estados de maturidade e desenvolvimento e serão alvo de uma harmonização entre si durante o desenvolvimento do Plano Diretor de Logística e Transportes - PDLT 2030, sendo priorizados os ajustes para as fontes que se mostraram mais relevantes neste estudo. Entretanto, este estudo já permite a avaliação preliminar da significância destas emissões, hierarquizando as fontes diretamente relacionadas às demandas de transporte de pessoas e de cargas, bem como identificar a necessidade de 
levantamentos mais acurados de fatores de emissão para uma reavaliação do próprio inventário em um segundo momento.

Cumpre salientar que a estimativa da emissão de $\mathrm{N}_{2} \mathrm{O}$ foi introduzida porque seu potencial gerador de efeito estufa é 325 vezes maior do que o do gás carbônico $\left(\mathrm{CO}_{2}\right)$. Como sua emissão é muito baixa e pouco conhecida foram utilizados fatores de emissão oriundos de fontes bibliográficas que estão superestimados,mas permitem a avaliação da relevância deste gás nas estratégias de controle do efeito estufa, o que se mostrou desprezível frente à emissão de $\mathrm{CO}_{2}$ das mesmas fontes.

Desta forma, pretende-se complementar a modelagem de alterações na matriz de transportes do Estado para o PDLT 2030, que está sendo desenvolvido, utilizando-se o inventário como balizador dos aumentos e reduções de emissão para todos os poluentes oriundos dos motores e veículos.

\section{Conceitos básicos utilizados nas estimativas deste inventário}

A metodologia de cálculo ${ }^{2}$ para a estimativa das emissões dos veículos leves, pesados e motociclos é a utilizada pela U.S.E.P.A. - Environmental ProtectionAgency, dos Estados Unidos, devidamente adaptada às condições brasileiras na medida da disponibilidade de dados locais. Esta metodologia considera que a emissão total anual de um determinado poluente atmosférico por veículos automotores é a somatória da emissão desse poluente por toda a frota circulante no ano em referência, considerando separadamente cada classe e idade dos veículos, bem como tipos de combustível, com seus respectivos fatores reais de emissão.

No caso de automóveis, motociclos, caminhões e ônibus, para cada anomodelo foram considerados a quilometragem média anual das frotas, os fatores de emissão dos veículos quando novos (FE), médios ou típicos dos poluentes em questão, o número de veículos das frotas circulantes, bem como as taxas de variação das emissões em função do uso do veículo ao longo do tempo, as quais são denominadas fatores de deterioração de emissões (FD). $\mathrm{O}$ emprego dos FD determinados em função do uso e do estado de manutenção é importante, pois confere aos valores calculados uma melhor representatividade da frota real e permite estimar os impactos de limites de emissão adotados nos Programas de Inspeção.

$$
\text { Emissão }_{\text {ton/ano }}=\Sigma\left(\mathrm{FE}_{\mathrm{g} / \mathrm{km}}{ }^{*} \mathrm{FD} \text { * Utilizaçãó } \mathrm{km}_{\mathrm{km}}{ }^{*}{ }^{*} \text { Frota }_{\text {milhōes }}\right)_{\text {ano-modelo }}
$$

Aparentemente simples, o cálculo desta expressão se torna complexo e a obtenção dos dados trabalhosa, na medida em que cada fator representa uma estatística altamente dependente de fatores tecnológicos, mas sobretudo dos hábitos da população, sendo de difícil caracterização, pois a obtenção dos parâmetros estatísticos é o aspecto mais delicado para a representatividade do inventário.

Entretanto, mesmo com alguma imprecisão, as tendências reveladas pelo inventário representam uma das melhores ferramentas para a avaliação dos 
programas diretamente ligados ao controle da poluição veicular e o planejamento de suas estratégias e seus requisitos futuros.

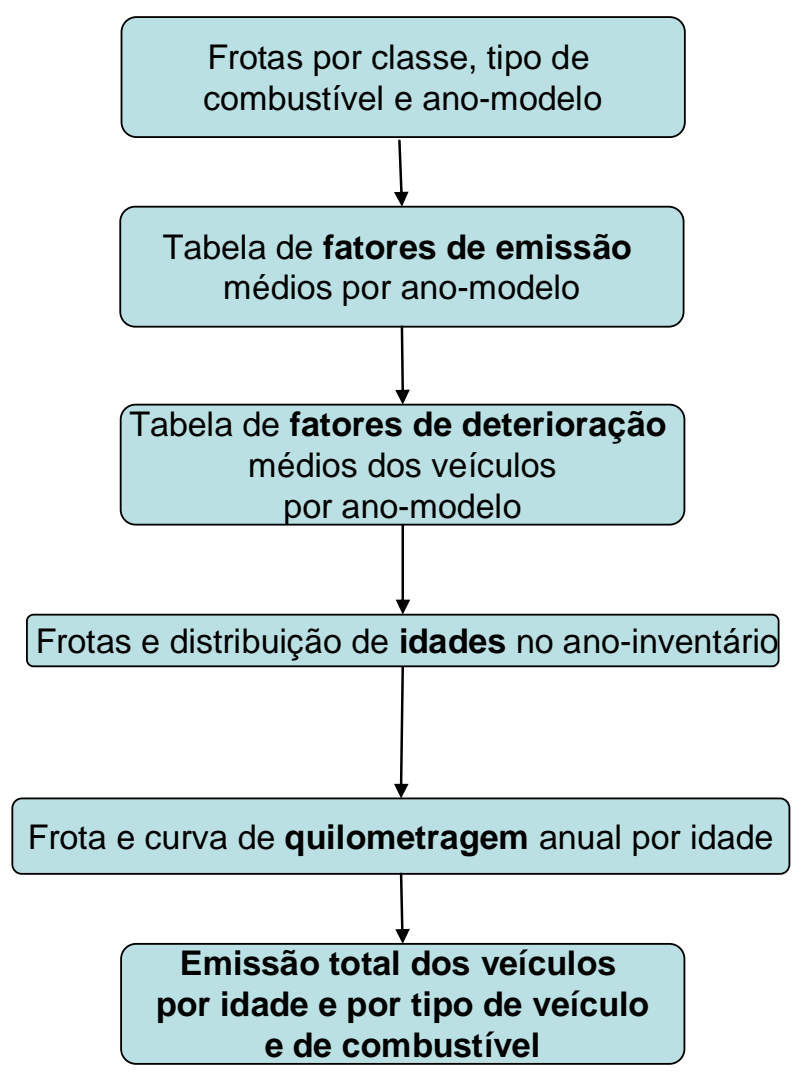

Figura 2.1 - Seqüência de cálculos do inventário

Seguindo o esquema da figura 2.1, o inventário é calculado separadamente para cada classe de veículo/combustível, considerando as somatórias dos produtos dos fatores intermediários (de emissão, de deterioração, percentual da frota, percentual de sucateamento, etc) para cada idade (ano-modelo) existente na frota daquele ano.

Nos casos do sistema ferroviário e hidroviário, os cálculos foram realizados de maneira simplificada, dada a falta de dados precisos para a caracterização das frotas de locomotivas e de embarcações, dos tipos e dos padrões tecnológicos de seus motores, das cargas transportadas etc.. Nestes casos, a bibliografia internacional apresenta fatores de emissão médios por padrão tecnológico, expressos em gramas de poluentes por $\mathrm{kg}$ de combustível consumido, sem o detalhamento de fatores de deterioração. Os resultados foram obtidos a partir dos consumos anuais de óleo diesel no Estado de São Paulo pelos setores ferroviário e hidroviário $^{3}$, associados aos fatores de emissão de motores diesel sem controle de emissões (padrão tecnológico dos caminhões pré-PROCONVE e motores norteamericanos empregados em locomotivas, os quais possuem fatores muito próximos destes. A revisão destes fatores, a partir da identificação detalhada das frotas brasileiras e seus padrões tecnológicos, será necessária nas próximas 
edições deste inventário, quando serão feitas as projeções futuras de vários cenários para o sistema de transportes do Estado de São Paulo.

Finalmente, no caso do sistema aeroviário, as estimativas se baseiam em cinco principais regimes de funcionamento dos aviões, nos quais as emissões são características: partida, taxiamento, decolagem, aproximação e cruzeiro ${ }^{4}$. Com os fatores de emissão típicos destes regimes de potência e as estatísticas dos tempos de permanência em cada um, por tipo de aeronave, aeroporto etc., as emissões são calculadas em duas fases distintas da operação:

- "Landing/Take-off cycle" (LTO), que é ociclo de descida desde a altitude de $1000 \mathrm{~m}$, taxiamento, partida e decolagem até atingir novamente esta altitude;

- Voo estabilizado em velocidade de cruzeiro.

Para os efeitos deste inventário preliminar, admitiu-se que o fator médio de emissão da frota brasileira de aviões comerciais nos dois ciclos LTO e cruzeiro sejam válidos para a média do Estado de São Paulo. Consequentemente, também foi admitido que a emissão anual guarde a mesma proporção entre os consumos de querosene de aviação do Estado e do país. Desta forma foram aproveitados os cálculos, levantamentos e estatísticas constantes do inventário do MCT realizados detalhadamente em 2006 por especialistas do Instituto de Aviação Civil ${ }^{5}$.

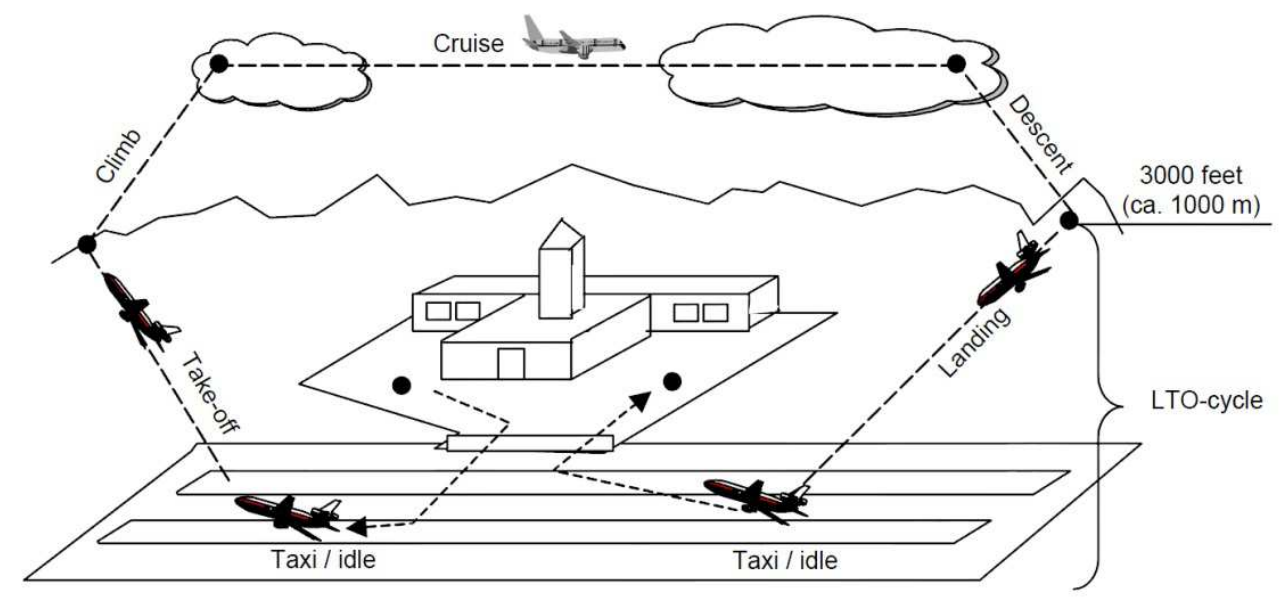

Figura 2.2 - Ciclo de operação de aeronaves para estimativas de emissões

\section{Dados e premissas utilizados neste inventário}

Mesmo com conhecimento parcial de determinados aspectos, será possível identificar as fontes mais relevantes de emissões para priorizar o aprimoramento das informações necessárias ao refinamento do inventário e o delineamento de estratégias de transporte voltadas ao equacionamento ambiental do estado de São Paulo.

Para comparar os diversos tipos de veículos, seus combustíveis e formas de utilização, foram considerados separadamente os veículos leves agasolina, álcool e flex;as motos a gasolina, flex e de motofrete (uso intenso); os veículos a diesel subdivididos em caminhões (até 30 ton), caminhões trator (acima de 30 ton), 
utilitários e ônibus, além dos aviões, ferrovias, hidrovias e as perdas evaporativas nos abastecimentos e transferências de combustíveis.

\subsection{Poluentes precursores da formação de ozônio e do efeito estufa}

A análise dos resultados de um inventário de emissões atmosféricas deve necessariamente ser feita em separado para cada poluente, pois tanto as fontes são específicas quanto os seus efeitos.

No caso dos poluentes precursores da formação de ozônio e do efeito estufa, entretanto, é necessário calcular o potencial de impacto ambiental de todos numa mesma base de comparação para fazer uma avaliação consistente e equilibrada das fontes de emissão em função dos compostos emitidos.

Assim, todas as emissões de VOCs (Compostos Orgânicos Voláteis), incluindo $\mathrm{HC}$ e etanol de escapamento, aldeídos, $\mathrm{HC}$ e etanol evaporados diretamente e HC de cárter, podem ser comparados em termos do potencial que cada composto possui para a formação de ozônio troposférico, que é o principal efeito ambiental desses poluentes. Para isso, foram tomados como referência os fatores de reatividade máxima incremental (MIR) para cada classe de poluentes, que representam o potencial de formação de ozônio de cada composto, com base nas tabelas propostas pelo CARB - California Air ResourcesBoard ${ }^{6}$. Para isso, foram utilizados os mesmos fatores propostos ao Grupo de Trabalho sobre Etanol não Queimado da AEA, baseados na composição nominal da gasolina brasileira, juntamente com o conceito de hidrocarbonetos equivalentes ${ }^{(\mathrm{d}) ;(7)}$.

A determinação dos fatores de emissão de etanol foi realizada para os veículos flex, cujas emissões estão bem caracterizadas. No caso de veículos mais antigos, a emissão de compostos orgânicos era caracterizada como "hidrocarbonetos totais", referentes à medição FID (detetor por ionização de chama) sem qualquer correção de massa ou de reatividade. Os estudos recentes desenvolvidos para os veículos flex confirmam que esta aproximação é aceitável em termos da formação de ozônio, pois a massa de etanol medida no FID é subestimada em $50 \%$ e compensa quase totalmente a diferença de reatividades. Por falta de dados e pela imprecisão que resultaria da extrapolação dos valores determinados para os veículos flex com tecnologia totalmente diversa dos veículos antigos, este inventário também considera os valores de $\mathrm{HC}$ como hidrocarbonetos para o cálculo do potencial de ozônio, quando não há medições de cada espécie dos compostos orgânicos.

Da mesma forma, os GEE (Gases de Efeito Estufa) podem ser comparados em termos dos respectivos potenciais de contribuição para o aquecimento global. No caso dos GEE emitidos pelos veículos, sabe-se que o óxido nitroso $\left(\mathrm{N}_{2} \mathrm{O}\right)$ e 0 metano $\left(\mathrm{CH}_{4}\right)$ possuem potenciais de contribuição para o efeito estufa 325 e 21,5 vezes maiores do que o do $\mathrm{CO}_{2}$, respectivamente, de forma que estas emissões

\footnotetext{
d Hidrocarbonetos equivalentes: é a massa de hidrocarbonetos, sem compostos oxigenados e caracterizados pela mesma reatividade dos gases resultantes da queima de gasolina, que produza quantidade de ozônio equivalente à produzida pelos gases de escapamento contendo os compostos oxigenados medidos efetivamente nos gases de escapamento emitidos pelo veículo.
} 
podem ser expressas em termos de $\mathrm{CO}_{2}$ equivalente para o aquecimento global, para se comparar as fontes veiculares entre si.

\subsection{Consumos de combustíveis}

Os consumos anuais de álcool, gasolina e óleo diesel foram tomados como a base estatística mais confiável relacionada à intensidade das operações de transporte no estado de São Paulo, a qual foi utilizada como referência do equilíbrio entre as demais hipóteses e estatísticas que caracterizam a intensidade das atividades de transporte (frotas e distribuição de quilometragens anuais em função da idade e tipo de uso do veículo).

Nos últimos anos, a percentagem de mistura de etanol na gasolina foi $24 \%$ em média, permitindo a estimativa e diferenciação da emissão de $\mathrm{CO}_{2}$ fóssil e renovável em função desta proporção. A percentagem de uso de etanol nos veículos flex foi determinadapela comparação de tendências das curvas mensais de vendas de etanol hidratado (E100) e gasolina C (E22), de jan/2000 a out/2012, fornecidas pela $A N P^{8}$ As regressões lineares das curvas de E22 e E100 antes de jan/2005 extrapoladas até 2011 permitem estimar a quantidade de gasolina C e etanol hidratado utilizados nos veículos a álcool e a gasolina nos anos subsequentes, apresentados na figura 3.1.

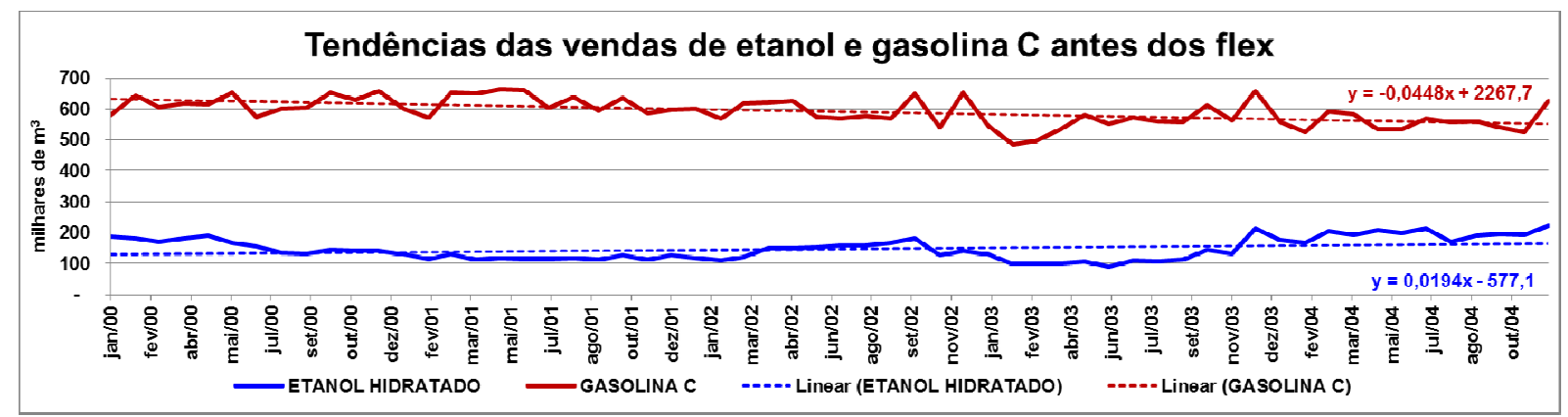

Figura 3.1 - Vendas de combustíveisentre janeiro de 2000 e dezembro de 2004

A diferença dessas quantidades para os totais observados mês a mês em 2011 fornecem uma estimativa dos volumes destes mesmos combustíveis utilizados nos veículos flex (figura 3.2). A média das percentagens mensais de consumo dos dois combustíveis pela frota de veículos flex foi da ordem de 49\% de E100 em 2011, embora neste ano em particular o consumo de um combustível em relação ao outro tenha sido bastante variado devido à flutuações do preço do etanol.

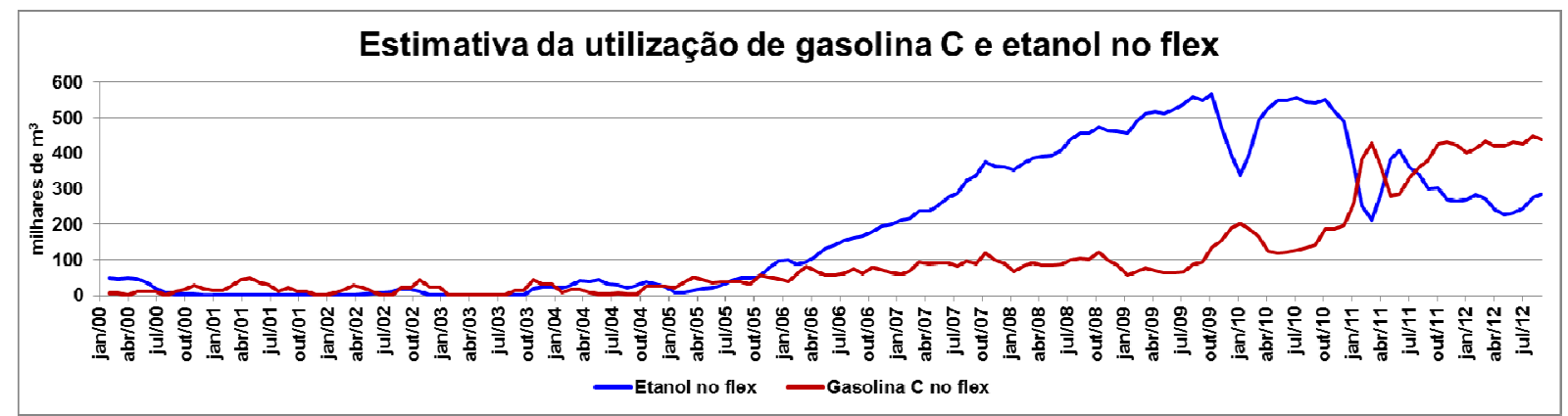


Figura 3.2 - Utilização de gasolina C e etanol nos veículos flexfuel

\subsection{Frotas circulantes e índices de sucateamento}

Os dados e estatísticas das frotas circulantes são bastante imprecisos, sendo mais confiáveis o número de veículos vendidos no mercado interno ou de licenciamentos iniciais apontados pela ANFAVEA (Associação Nacional dos Fabricantes de Veículos Automotores) em seu Anuário Estatístico da Indústria Automobilística ${ }^{9}$, que correspondem às diversas frotas na sua origem.

Para determinar a frota realmente circulante, as curvas de sucateamento adotadas pelo MCT e a CETESB em seus inventários foram confrontadas com as proporções de veículos em função da idade, encontradas nas frotas inspecionadas do Programa I/M-SP, e ajustadas segundo equações de Gompertz.

\subsection{Fatores de emissão para veículos leves, motociclos e similares}

Os fatores de emissão dos poluentes regulamentados e de $\mathrm{CO}_{2}$ destes veículos são os publicados pela CETESB para cada ano de fabricação. Para os poluentes não regulamentados foram utilizados fatores de emissão obtidos em bibliografia, muitas vezes associado ao consumo de combustível ou a outro fator conhecido de emissão.

3.4.1. Emissão de etanol não queimado: foram adotados os seguintes valores característicos:

- Veículos a álcool (antigos): devido à ausência de dados mais detalhados, a emissão de componentes orgânicos é assumida como sendo o fator de emissão de THC (hidrocarbonetos totais medidos pelo FID), como se fossem hidrocarbonetos;

- Veículos flex: desde 2003, os fatores de emissão de HC expressam apenas a parcela de NMHC (hidrocarbonetos não metano), descontada a massa de etanol. Em estudo recente, a fração de etanol foi recalculada e revelada no âmbito de um Grupo de Trabalho da AEA para avaliação do seu potencial de formação de ozônio comparado ao dos NMHC. A equivalência destes dois compostos baseia-se no potencial de formação de ozônio de cada um, calculado a partir da reatividade fotoquímica (MIR). A emissão real de etanol aceita peloGrupo de Trabalho da AEA foi tomada como a média das estatísticas $(0,085 \mathrm{~g} / \mathrm{km})$ levantadas pela EnvironMentality, que é ligeiramente superior à mediana dos valores $(0,062 \mathrm{~g} / \mathrm{km})$, ambas ainda carecendo da ponderação pela produção de veículos.

\footnotetext{
${ }^{e}$ Os poluentes regulamentados para veículos leves do ciclo Otto são $\mathrm{CO}, \mathrm{HC}$, NOx, aldeídos (CHO), expressos em $\mathrm{g} / \mathrm{km}$, além das emissões evaporativas de combustível, expressas em $\mathrm{g} / \mathrm{teste}$. A emissão de etanol pelo escapamento é considerada como HC nesses relatórios, sendo subestimada em termos de componentes orgânicos totais, porém a sua reatividade fotoquímica é menor.
}

${ }^{\mathrm{f}}$ Como não há dados mais precisos, esta aproximação é aceitável em termos dos efeitos desta emissão na formação de ozônio. 
3.4.2. Aldeídos emitidos por motociclos: fatores de emissão assumidos pela EnvironMentality com base nos automóveis com tecnologias semelhantes, em cada fase do PROMOT:

- $0,050 \mathrm{~g} / \mathrm{km}$ até 2002 (= leves até 1985)

- $0,040 \mathrm{~g} / \mathrm{km}$ de $2003 / 2004$ (= leves L1)

- $0,025 \mathrm{~g} / \mathrm{km}$ de $2005 / 2008$ (= leves L2)

- $0,007 \mathrm{~g} / \mathrm{km}$ gasolina de 2009 até 2011

○ $0,012 \mathrm{~g} / \mathrm{km}$ flex com etanol de 2009 até 2011

3.4.3. Fatores de emissão evaporativa de combustível: neste inventário preliminar foram consideradas somente as perdas por evaporação no resfriamento do veículo após um trajeto padrão ("hot soak") e as emanações provocadas por um aquecimento diurno, ambas assumidas como 3 vezes por dia (correspondentes a 3 ciclos de condução padrão/dia ou $15.330 \mathrm{~km} / \mathrm{ano}$ ), nos 365 dias do ano, expressas em g/ano. Considerando esta quilometragem média anual e os fatores brasileiros, as emissões evaporativas resultaram equivalentes a $1,68 \mathrm{~g} / \mathrm{km}$ para modelos até 1989 (a EPA recomenda 2,5g/km para veículos antigos, como referência).

Analisando as estatísticas de veículos "rejeitados" pelo Programa I/M-SP pelos itens "fixação, conexões e mangueiras do cânister, irregulares" e "cânister ausente ou danificado", verifica-se que apenas $0,7 \%$ da frota de automóveis apresentam estes defeitos, motivo pelo qual optou-se por não incluir nenhum fator de deterioração para as emissões evaporativas.

3.4.4.Fatores de emissão de $\mathrm{HC}$ do cárter: como a emissão de cárter dos veículos antigos não é medida nem divulgada, foi utilizado o valor adotado pelaEPA $(2,5 \mathrm{~g} / \mathrm{km})$ para os veículos leves fabricados até 1977 e motociclos até 2005 (veículos sem controle do cárter). A análise dos motivos de reprovação pelo Programa I/M-SP indicou que cerca de $2 \%$ da frota de automóveis foi rejeitada por "sistema PCV (ventilação positiva do cárter) ausente ou danificado" ou "fixação, conexões e mangueiras do sistema PCV, irregulares". Como a real influência desses itens de inspeção sobre as emissões ainda não está convenientemente quantificada, considerou-se que cerca de metade desses casos tem influência total sobre as emissões. Por isso, foi aplicado o mesmo fator de emissão aceito para os veículos antigos $(2,5 \mathrm{~g} / \mathrm{km})$ para $1 \%$ dos veículos fabricados após 1977.

\subsubsection{Fatores de emissão não regulamentados: $\mathrm{MP}, \mathrm{CH}_{4}$ e $\mathrm{N}_{2} \underline{\mathrm{O}}$}

A emissão de material particulado em motores do ciclo Otto não é medida no Brasil, mas a literatura fornece alguma indicação. Para efeito de comparação da ordem de grandeza desta emissão entre as frotas Otto e Diesel, foram assumidos fatores de emissão tipicamente de $0,05 \mathrm{~g} / \mathrm{km}$ para os veículos leves em geral e 
$0,03 \mathrm{~g} / \mathrm{km}$ para os veículos flex abastecidos com etanol, conforme indicado pela bibliografia internacional e EPA.

Com relação à emissão de metano, somente os veículos a gás natural são submetidos a esta medição. Para os demais, esta emissão é pouco conhecida, exceto os valores de $\mathrm{CH}_{4}$ dos veículos fabricados a partir de 2004, por força da determinação de NMHC, porém estes não são publicados. Via de regra, nos processos de certificação este valor é da ordem de $40 \%$ do THC ou $70 \%$ do NMHC nos veículos flex funcionando com etanol e $27 \%$ do THC ou $37 \%$ do NMHC nos mesmos veículos funcionando com gasool (E22). Entretanto, não existem informações sobre os fatores de deterioração da emissão de $\mathrm{CH}_{4}$ nestes veículos, que devem ser menores do que os de $\mathrm{HC}$ porque os catalisadores não atuam fortemente sobre a redução de metano. Para efeito de estimativa da ordem de grandeza dessa emissão, este estudo assume que permanecem válidas estas proporções sobre os resultados finais, superestimando as conclusões.

A emissão de $\mathrm{N}_{2} \mathrm{O}$ foi muito pouco investigada no Brasil, dispondo-se apenas de alguns dados esparsos, que indicam valores de $6 \mathrm{mg} / \mathrm{km}$ para motores a álcool, $27 \mathrm{mg} / \mathrm{km}$ para motores a gasool e $10 \mathrm{mg} / \mathrm{km}$ medido em apenas um utilitário a diesel.A literatura internacional também cita valores bastante dispersos, de forma que se optou por adotar as médias mais altas entre os valores considerados característicos numa amostragem das mais extensas ${ }^{10}$. A literaturatambém considera este poluente como um fator fortemente dependente da tecnologia de controle de emissões ${ }^{11}$.

A ausência de dados efetivamente medidos levou a associar os padrões tecnológicos dos veículos brasileiros aos fatores de emissão de $\mathrm{N}_{2} \mathrm{O}$ citados por Huai, adequando-se ao tamanho do veículo com base no consumo de combustível (expresso emmg_ $\mathrm{N}_{2} \mathrm{O} /$ litro de combustível consumido ou em mg_ $\mathrm{N}_{2} \mathrm{O} / \mathrm{kg}$ de $\mathrm{CO}_{2}$, para estendê-lo aos veículos a álcool e flex na mesma proporção à energia produzida, conforme a referência do ciclo de condução padrão.

\subsubsection{Fatores de deterioracão}

Devido à falta de dados brasileiros acerca do crescimento das emissões em função da degradação dos veículos em uso normal, os fatores de deterioração dos veículos leves foram estimados a partir de um levantamento por sensoriamento remoto (Remote SensingDevice - RSD), realizado no ano 2000 em São Paulo, em Brasília e no Rio de Janeiro, no qual foram medidas as emissões de $\mathrm{CO}, \mathrm{HC}$ e $\mathrm{NOx}^{12}$, que deram origem aos primeiros fatores brasileiros realistas de degradação anual para os três poluentes mencionados, que estão coerentes com os resultados do Programa l/M-SP.

Tais fatores foram também estendidos para as motocicletas, resguardadas as semelhanças de padrões tecnológicos (carburador, catalisador, injeção eletrônica etc.) de acordo com as fases do PROCONVE e PROMOT.

Através de um novo estudo que correlacionou as medições por sensoriamento remoto em mais de 60 mil veículos com as realizadas em marcha lenta nos Centros de Inspeção do Programa I/M-SP ${ }^{13}$, o qual validou as medições 
por sensoriamento remoto para a frota e os combustíveis brasileiros, bem como evidenciou que a desconformidade média da frota de veículos leves é da ordem de apenas $2,7 \%$ para o NOx, percentual que se eleva a quase $20 \%$ entre os veículos reprovados no I/M-SP.

Por analogia com os processos de formação e tratamento dos hidrocarbonetos, o fator de degradação para aldeídos e etanol não queimado foi tomado como igual ao dos hidrocarbonetos emitidos pelo escapamento.

As emissões de $\mathrm{CO}_{2}$ fóssil e renovável não são submetidas a fatores de degradação, pois são diretamente relacionadas ao consumo de combustível, o qual não sofre alterações significativas com o estado de conservação ou com a idade do veículo. Também não foram definidos fatores de deterioração para os poluentes não regulamentados, tendo em vista a grande imprecisão dos fatores de emissão adotados e por esta estimativa se destinar apenas à determinação da ordem de grandeza dessas emissões.

\subsection{Veículos a diesel}

Este grupo foi subdividido em caminhões, caminhões trator, utilitários e ônibus, para fins do inventário, posto que suas características de fator de emissão, curvas de idade e quilometragem anual média são substancialmente diferentes.

\subsubsection{Fatores de emissão}

Para os veículos pesados, a CETESB divulga valores médios não ponderados das emissões de $\mathrm{CO}, \mathrm{HC}$, NOx e particulados dos motores, medidos em $\mathrm{g} / \mathrm{kWh}$. A conversão destes fatores de emissão dos motores para os de veículos (expressos em $\mathrm{g} / \mathrm{km}$ ) foi realizada por metodologia desenvolvida pela EnvironMentality, através da correlação entre os consumos de energia do motor e do veículo. Tanto os valores de consumo dos motores, em $\mathrm{g} / \mathrm{kWh}$, quanto dos veículos, em $\mathrm{km} / \mathrm{l}$, foram obtidos dos acervos de informações da EnvironMentality e do Prof. Francisco E. B. Nigro, levantadas com diversas empresas transportadoras, fabricantes destes veículos e confrontadas com modelos de cálculo da demanda energética de veículos, conforme apresentados na figura 3.2.

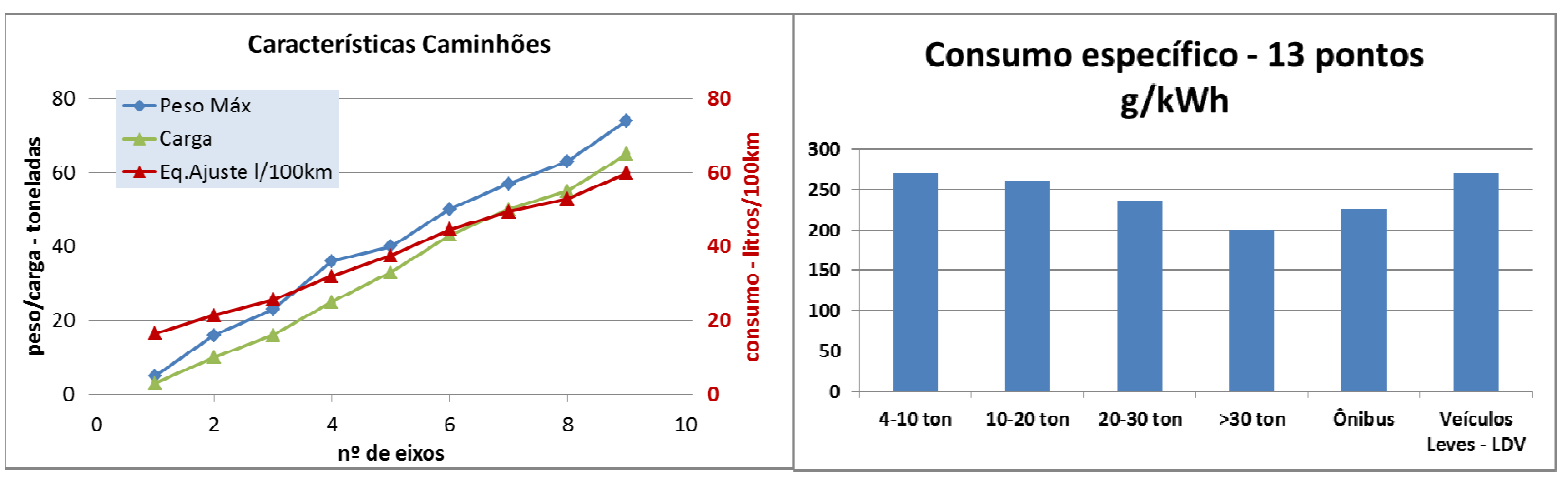

Figura 3.2 - Consumo típico de combustível de veículos Diesel 
A emissão de material particulado medida com o combustível de referência é corrigida em função do teor de enxofre do óleo diesel comercial, com base em um teor médio de enxofre admitido para o Estado. Como o percentual de enxofre no combustível varia entre a capital, que já adotava o diesel com 500ppm de enxofre (S500) em 2011, e o interior, que ainda utilizava o S1800, foi feito o cálculo da concentração média ponderada pelos percentuais de cada tipo de veículo entre a cidade de SP e o interior.

Para os poluentes não regulamentados, os fatores de emissão são muito escassos na bibliografia, o que obriga a adoção, como premissas, de fatores proporcionais à emissão de $\mathrm{HC}$, que foram calculados diretamente sobre os resultados finais do inventário. Segundo a EPA ${ }^{14}$, a emissão de aldeídos por motores anteriores ao PROCONVE chega a $40 \%$ da emissão de $\mathrm{HC}$ ou mais - por exemplo, Mercedes OM352; Caterpillar 3406. Abrantes, $R .{ }^{15}$ constatou casos na faixa de 151 a $1406 \mathrm{mg} /$ litro de combustívelconsumido, em veículos leves. Com base nestas referências, foram adotados os fatores de $38 \%$ da emissão de HC para os motores mais antigos (até 2004) e 20\% a partir de 2005 .

A influência do uso de biodiesel foi estimada sobre os resultados finais do inventário somente para o cálculo da emissão de $\mathrm{CO}_{2}$ fóssil e renovável, considerando-se a massa de carbono renovável em $5 \%$ do volume de combustível consumido. Admitindo-se a emissão de 2640 e $2450 \mathrm{~kg} \mathrm{CO} / /$ itro e densidades de 0,84 e 0,88 para o óleo diesel e o biodiesel, respectivamente, conclui-se que as proporções de $\mathrm{CO}_{2}$ fóssil e renovável para o $\mathrm{B} 5$ são $95,3 \%$ e $4,7 \%$. Não foram consideradas as variações das emissões dos demais poluentes nem a variação de reatividade da emissão de $\mathrm{HC}$.

A emissão do cárter foi tomada como sendo $2 \%$ da emissão de $\mathrm{HC}$ de escapamento, conforme aceito pela EPA ${ }^{16}$.

De acordo comEPA ${ }^{17}$ as emissões evaporativas de veículos diesel podem ser assumidas como $5,3 \%$ das emissões de $\mathrm{HC}$ de escapamento, bem como a emissão de $\mathrm{CH}_{4}$ também é diretamente proporcional a essas emissões. Complementarmente, a $E P A^{18}$, indica o fator de emissão de $0,25 \mathrm{~g}_{-} \mathrm{CH}_{4} / \mathrm{kg}$ de óleo diesel, para motores sem controle de emissões, que corresponde a $8 \%$ da emissão de HC, proporção esta utilizada neste inventário, como referência inicial para todas as tecnologias. A mesma publicação sugere o fator de emissão de $0,08 \mathrm{~g} \_\mathrm{N}_{2} \mathrm{O} / \mathrm{kg}$ de combustível, para motores Diesel em geral, que foi adotado neste inventário.

\subsubsection{Fatores de deterioração}

Para os veículos diesel, não há dados brasileiros que permitam estimativa semelhante e, por isso, foram adotados os fatores de deterioração recomendados pelo Compilationof Emission Factors da EPA - AP- $42^{19}$.

Os fatores de deterioração da EPA são dados como acréscimos de emissão em gramas de poluente por quilômetro, para cada $10.000 \mathrm{~km}$. Estes fatores foram convertidos para porcentual de acréscimo em função da quilometragem acumulada, aplicado sobre os fatores de emissão calculados pela EnvironMentality, considerando a idade limite de 20 anos como deterioração máxima do veículo. 
Da mesma forma como aplicado para os veículos do ciclo Otto, parte da frota foi considerada como não conforme, sendo que para esses veículos, o fator de deterioração considerado foi o máximo aplicado para os veículos normais (de 20 anos de idade) independentemente da idade do veículo. Os porcentuais de veículos degradados correspondem aos índices de não aprovação (índices de reprovação e rejeição somados) do programa l/M-SP (tabela 3.1).

\section{Tabela 3.1: Porcentual de veículos considerados como não conformes}

\begin{tabular}{|l|c|}
\hline Tipo de veículo & $\begin{array}{c}\text { \% de não aprovação } \\
\text { (I/M-SP) }\end{array}$ \\
\hline Caminhão & $54 \%$ \\
\hline Caminhão trator & $46 \%$ \\
\hline Utilitários diesel & $41 \%$ \\
\hline Ônibus & $40 \%$ \\
\hline
\end{tabular}

\subsection{Transporte aéreo}

Há duas diretrizes para estimar as emissões de gases poluentes e de efeito estufa devidas ao transporte aéreo. O método mais simplificado baseia-se apenas no consumo de combustíveis do setor e em fatores médios de emissão, expressos em $\mathrm{g} / \mathrm{kg}$ de combustível, enquanto o método detalhado baseia-senas estatísticas do número de operações de decolagem/aterrissagem e em fatores de emissão característicos de cada regime de operação, como descrito no capítulo 2.

O $\mathrm{MCT}^{5}$ avaliou a emissão anual de poluentes do setor de transporte aéreo em 2006, utilizando o método mais detalhado, porém em termos das estatísticas operacionais dos voos nacionais e internacionais que abrangem o país como um todo.

No presente inventário, não foi possível estratificar as informações destas estatísticas para o Estado de São Paulo. Entretanto, é admissível que as proporções encontradas nos níveis nacionais sejam as mesmas deste Estado, calculadas pela proporção dos consumos anuais de querosene de aviação divulgados pela Secretaria de Energia ${ }^{3}$.

Em revisões futuras esta estimativa deve ser refeita com dados-base paulistas devidamente levantados para o aprimoramento do inventário, entretanto o presente resultado pode ser tomado como uma primeira referência para comparação com os outros modos de transporte e verificar a relevância do setor aéreo nesta questão.

\subsection{Transporte ferroviário e hidroviário}

Nestes casos também há duas diretrizes para estimar as emissões de gases poluentes e de efeito estufa devidas aosmodos de transporte ferroviário e 
hidroviário. O método mais simplificado baseia-se apenas no consumo de combustíveis do setor e em fatores médios de emissão, expressos em $\mathrm{g} / \mathrm{kg}$ de óleo diesel consumido, enquanto o método detalhado baseia-se em fatores de emissão característicos dos ciclos típicos das operações principais e suas estatísticas de ocorrência na área de interesse.

Os motores dos trens e embarcações utilizados no Brasil são fabricados sob padrões tecnológicos isentos de exigências ambientais, cujos fatores de emissão são conhecidos a partir de informações bibliográficas internacionais e de motores de caminhões brasileiros anteriores ao PROCONVE.

Os fatores de emissão sugeridos pela EPA $^{23}$ para locomotivas sem dispositivos de redução de emissões (Tier 0) são muito próximos aos dos motores rodoviários brasileiros de caminhão, indicando grande probabilidade de serem representativos das ferrovias nacionais funcionando, inclusive, com óleo diesel comercial. Adicionalmente, a emissão de aldeídos pode ser estimada a partir de uma proporcionalidade aos hidrocarbonetos, assim como as emissões de $\mathrm{CH}_{4}$ e $\mathrm{N}_{2} \mathrm{O}$, todas indicadas pela EPA ${ }^{20}$. Pelo mesmo raciocínio, os mesmos fatores de emissão foram também estendidos ao transporte hidroviário, todos expressos em gramas de poluente por kg de óleo diesel.

É importante ressaltar que a ANTT divulgou o consumo de combustível e o momentum de transporte do setor ferroviário, em tku - tonelada útil*km percorrido, de cada ferrovia brasileira, o que permite uma análise geral da eficiência deste modo de transporte, comparativamente à média das ferrovias norte americanas ${ }^{21}$ e ao transporte rodoviário brasileiro. Tal índice também permite comparar a produção de poluentes por tku do sistema ferroviário com a dos outros modos de transporte, 0 que resultou muito ruim, indicando ineficiência das nossas ferrovias ou deficiência das estatísticas disponíveis e a necessidade de maior aprofundamento nestas informações.

\subsection{Abastecimentos e transferências de combustíveis}

O controle da emissão evaporativa durante o abastecimento de reservatórios de combustíveis líquidos não foi implantado, mas tem sido considerado recentemente em estudos pela CETESB e pela AEA. Trata-se de um deslocamento de vapor saturado do combustível em igual volume do líquido transferido, cujo controle pode ser baseado na simples transferência recíproca entre os dois reservatórios (abastecedor e abastecido), especialmente nas transferências das bases para o caminhão tanque transportador e deste para o posto de distribuição. Já entre o posto e o veículo consumidor, esta operação torna-se menos eficaz pela dificuldade operacional inerente ao fracionamento em pequenos volumes e uma boa vedação nos bocais de abastecimento. Para esta terceira fase, cogita-se a implantação de sistemas ORVR (onboardrefueling vapor recovery), que consiste de uma modificação no sistema de controle de emissões evaporativas do próprio veículo, aumentando o seu reservatório de carvão ativado para adsorver volumes maiores de vapor. 
A estimativa desta emissão é calculada a partir da densidade do vapor de combustível e do volume comercializado na região de interesse. Os fatores numéricos foram obtidos na literatura especializada e a estimativa para o Estado de São Paulo foi desenvolvida inicialmente para o Grupo de Trabalho da AEA, que estuda a emissão de compostos orgânicos pelos veículos flex ${ }^{22}$, e incluída neste inventário preliminar como referência para comparação com outras fontes de compostos orgânicos relacionadas aos transportes.

\section{Interpretação dos resultados e análise comparativa}

As emissões totais anuais estão apresentadas em grupos, a saber, emissões orgânicas segundo sua origem (cárter, evaporativa e escapamento, inclusive a especiação em aldeídos e etanol), demais poluentes locais regulamentados (CO, NOx e material particulado) e GEE $\left(\mathrm{CO}_{2}, \mathrm{CH}_{4}\right.$ e $\left.\mathrm{N}_{2} \mathrm{O}\right)$. Nesta primeira tabela mais detalhada já estão apresentadas as somas dos hidrocarbonetos das diversas origens e as emissões de etanol (EtOH) que, juntamente com os aldeídos são os três precursores orgânicos básicos de ozônio, que reagem com os NOx.

Esta primeira estimativa inclui o cálculo pelo balanço de carbono dos volumes de combustível consumidos por todos os setores, segundo as premissas adotadas. A comparação destes consumos com os volumes de vendas no Estado evidenciou excelente precisão do inventário, que variou entre $-2 \%$ a $+2 \%$, com exceção do etanol consumido nos veículos a álcool que foi de $-7 \%$ dadas as imprecisões da medição de HC nestes veículos. Estes desvios validaram as premissas assumidas no inventário e foram utilizados como fatores de correção de todas as emissões para a geração da tabela 4.1 do inventário ajustado que guarda perfeita coerência entre os gases emitidos e os combustíveis consumidos nos transportes.

Tabela 4.1 - Emissões anuais ajustadas, por origem e tipo de veículo - ton/ano

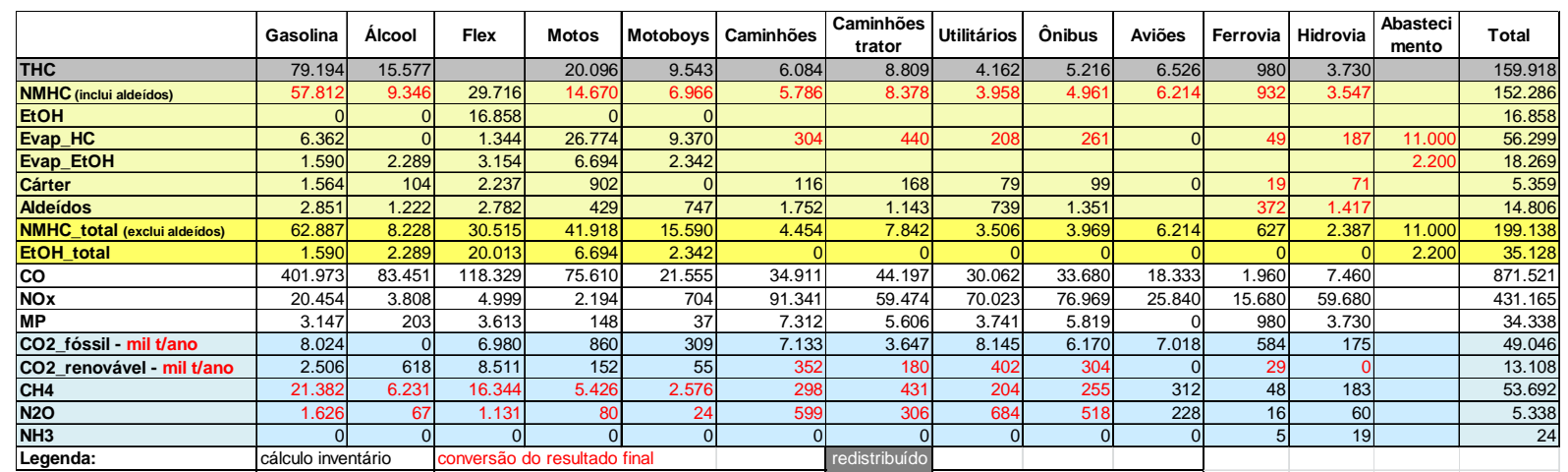




\begin{tabular}{|c|c|c|c|c|c|c|c|c|c|c|c|c|c|c|}
\hline & Gasolina & Álcool & Flex & Motos & Motoboys & Caminhões & $\begin{array}{c}\text { Caminhões } \\
\text { trator }\end{array}$ & Utilitários & Ônibus & Aviões & Ferrovia & Hidrovia & \begin{tabular}{|c|} 
Abasteci \\
mento
\end{tabular} & Total \\
\hline THC & $50 \%$ & $10 \%$ & $0 \%$ & $13 \%$ & $6 \%$ & $4 \%$ & $6 \%$ & $3 \%$ & $3 \%$ & $4 \%$ & $1 \%$ & & $0 \%$ & $100 \%$ \\
\hline NMHC & $38 \%$ & $6 \%$ & $20 \%$ & $10 \%$ & $5 \%$ & $4 \%$ & $6 \%$ & $3 \%$ & $3 \%$ & $4 \%$ & $1 \%$ & $2 \%$ & $0 \%$ & $100 \%$ \\
\hline $\mathrm{EtOH}$ & $0 \%$ & $0 \%$ & $100 \%$ & $0 \%$ & $0 \%$ & $0 \%$ & $0 \%$ & $0 \%$ & $0 \%$ & $0 \%$ & $0 \%$ & $0 \%$ & $0 \%$ & $100 \%$ \\
\hline Evap_HC & $11 \%$ & $0 \%$ & $2 \%$ & $48 \%$ & $17 \%$ & $1 \%$ & $1 \%$ & $0 \%$ & $0 \%$ & $0 \%$ & $0 \%$ & $0 \%$ & $20 \%$ & $100 \%$ \\
\hline Evap_EtOH & $9 \%$ & $13 \%$ & $17 \%$ & $37 \%$ & $13 \%$ & $0 \%$ & $0 \%$ & $0 \%$ & $0 \%$ & $0 \%$ & $0 \%$ & $0 \%$ & $12 \%$ & $100 \%$ \\
\hline Cárter & $29 \%$ & $2 \%$ & $42 \%$ & $17 \%$ & $0 \%$ & $2 \%$ & $3 \%$ & $1 \%$ & $2 \%$ & $0 \%$ & $0 \%$ & $1 \%$ & $0 \%$ & $100 \%$ \\
\hline Aldeídos & $19 \%$ & $8 \%$ & $19 \%$ & $3 \%$ & $5 \%$ & $12 \%$ & $8 \%$ & $5 \%$ & $9 \%$ & $0 \%$ & $3 \%$ & $10 \%$ & $0 \%$ & $100 \%$ \\
\hline NMHCtotal & $32 \%$ & $4 \%$ & $15 \%$ & $21 \%$ & $8 \%$ & $2 \%$ & $4 \%$ & $2 \%$ & $2 \%$ & $3 \%$ & $0 \%$ & $1 \%$ & $6 \%$ & $100 \%$ \\
\hline EtOH total & $5 \%$ & $7 \%$ & $57 \%$ & $19 \%$ & $7 \%$ & $0 \%$ & $0 \%$ & $0 \%$ & $0 \%$ & $0 \%$ & $0 \%$ & $0 \%$ & $6 \%$ & $100 \%$ \\
\hline CO & $46 \%$ & $10 \%$ & $14 \%$ & $9 \%$ & $2 \%$ & $4 \%$ & $5 \%$ & $3 \%$ & $4 \%$ & $2 \%$ & $0 \%$ & $1 \%$ & $0 \%$ & $100 \%$ \\
\hline NOx & $5 \%$ & $1 \%$ & $1 \%$ & $1 \%$ & $0 \%$ & $21 \%$ & $14 \%$ & $16 \%$ & $18 \%$ & $6 \%$ & $4 \%$ & $14 \%$ & $0 \%$ & $100 \%$ \\
\hline MP & $9 \%$ & $1 \%$ & $11 \%$ & $0 \%$ & $0 \%$ & $21 \%$ & $16 \%$ & $11 \%$ & $17 \%$ & $0 \%$ & $3 \%$ & $11 \%$ & $0 \%$ & $100 \%$ \\
\hline CO2fóssil - mil t/ano & $16 \%$ & $0 \%$ & $14 \%$ & $2 \%$ & $1 \%$ & $15 \%$ & $7 \%$ & $17 \%$ & $13 \%$ & $14 \%$ & $1 \%$ & $0 \%$ & $0 \%$ & $100 \%$ \\
\hline CO2renovável - mil t/a & $19 \%$ & $5 \%$ & $65 \%$ & $1 \%$ & $0 \%$ & $3 \%$ & $1 \%$ & $3 \%$ & $2 \%$ & $0 \%$ & $0 \%$ & $0 \%$ & $0 \%$ & $100 \%$ \\
\hline CH4 & $40 \%$ & $12 \%$ & $30 \%$ & $10 \%$ & $5 \%$ & $1 \%$ & $1 \%$ & $0 \%$ & $0 \%$ & $1 \%$ & $0 \%$ & $0 \%$ & $0 \%$ & $100 \%$ \\
\hline N2O & $30 \%$ & $1 \%$ & $21 \%$ & $1 \%$ & $0 \%$ & $11 \%$ & $6 \%$ & $13 \%$ & $10 \%$ & $4 \%$ & $0 \%$ & $1 \%$ & $0 \%$ & $100 \%$ \\
\hline
\end{tabular}

\subsection{Poluentes locais}

Os resultados deste inventário confirmam as estratégias já adotadas para o controle de emissões dos modos rodoviários de transportes, mas cabe analisá-los em detalhes para melhor compreensão do problema e delineamento de estratégias mais abrangentes, incluindo as mudanças modais como combate à poluição do ar provocada pelos transportes.

a) monóxido de carbono:

A análise dos poluentes locais e regulamentados confirma o conhecimento já generalizado de que os automóveis a gasolina ainda respondem por $46 \%$ da emissão de CO.

A distribuição da emissão de CO por ano de fabricação evidencia que uma grande parte se deve aos veículos a gasolina de 1989 a 1997, portanto corrigível apenas pelo programa de inspeção e manutenção e pelo sucateamento de frota. Entretanto, os veículos flex e as motocicletas estão assumindo uma nova posição de destaque que merecem atenção, indicando a necessidade de novas regulamentações mais restritivas ou de uma política de redução de uso do transporte individual, inclusive por motos. Os demais modos de transporte não são muito relevantes para a emissão de CO.

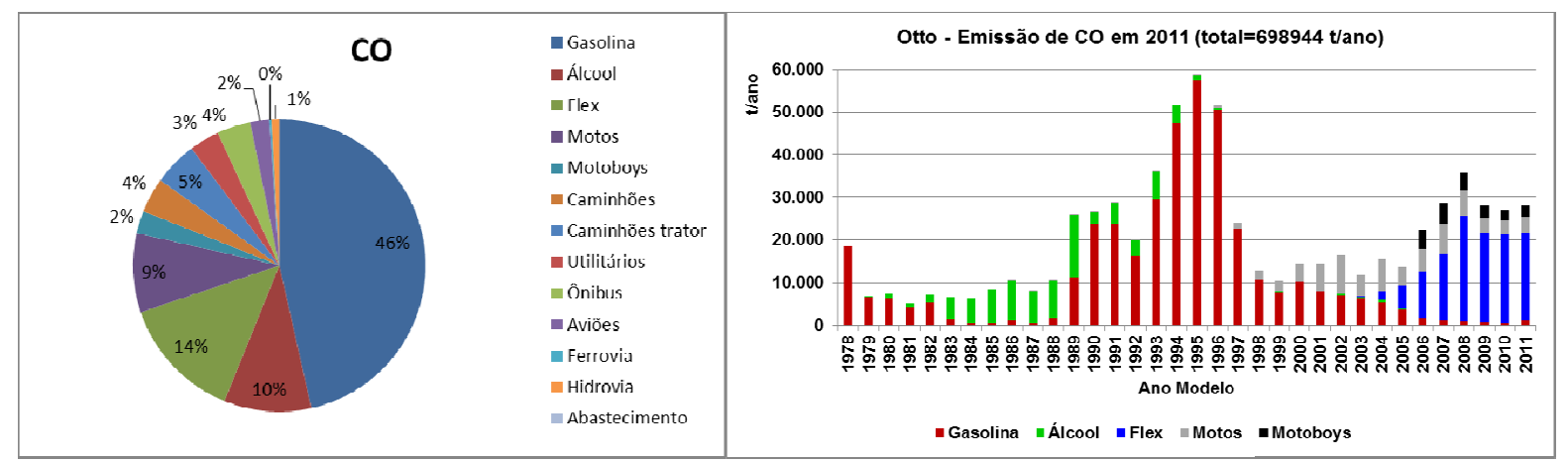

Figura 4.1 - Distribuições da emissão de CO por categoria de veículo e por ano de fabricação dos veículos de transporte individual 


\section{b) Material particulado}

Os veículos rodoviários a diesel respondem por $64 \%$ das emissões de material particulado, tendo decrescido nos últimos anos por força do PROCONVE. Deve-se ressaltar que este inventário aponta uma emissão crescente deste poluente pelos motores do ciclo Otto, já atingindo a casa dos $20 \%$, em razão do maior crescimento da frota, e até hoje não foram alvo de regulamentação para este poluente. Dadas as incertezas acerca dos fatores de emissão de MP pelos veículos Otto, este fato justifica a realização de medições em todos os modelos de automóveis e derivados para aprimorar o conhecimento deste aspecto.

De qualquer forma, a emissão de MP pelas hidrovias e ferrovias já equivalem à dos veículos do ciclo Otto e ultrapassam a dos utilitários a diesel, devendo ser priorizado o seu controle quando da expansão destes modos de transporte.

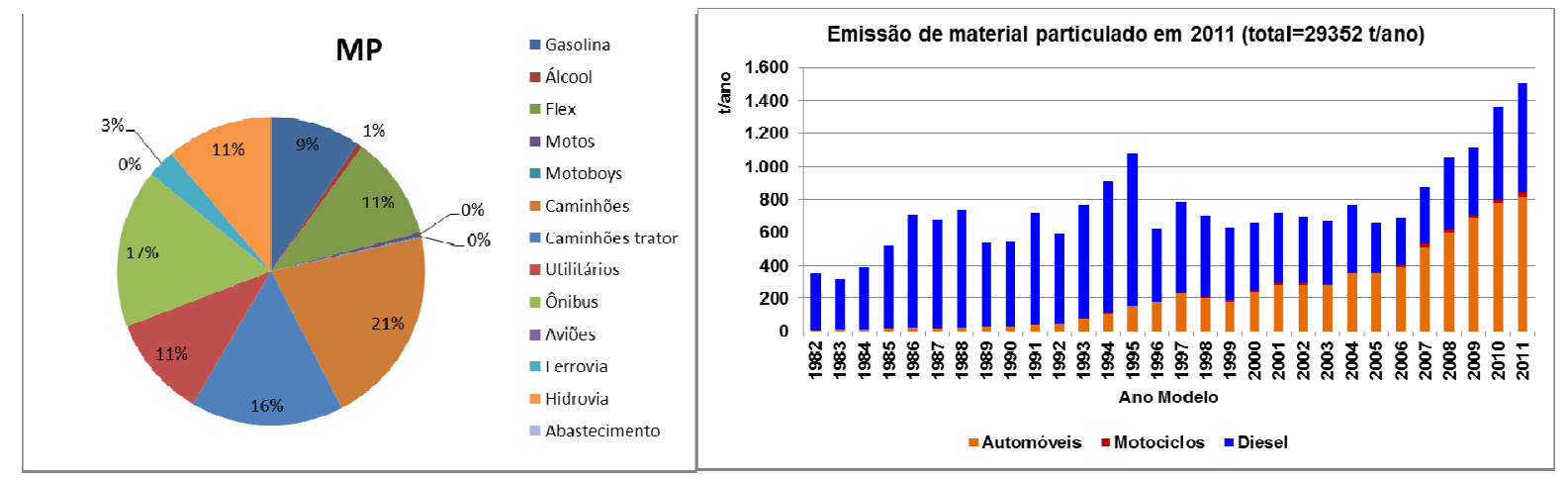

Figura 4.2 - Distribuições da emissão de MP por categoria de veículo e por ano de fabricação dos veículos rodoviários

\section{c) Óxidos de nitrogênio}

Os veículos rodoviários a diesel respondem por quase $70 \%$ das emissões de NOx, de maneira crescente nos últimos anos de fabricação, o que justifica a adoção de medidas mais severas para os motores Diesel rodoviários, uma vez que os veículos do ciclo Otto já sofreram as restrições necessárias. Apesar da reduzida participação das ferrovias e hidrovias no cenário atual, é digno de nota que estas emitem mais do que a frota de utilitários a diesel que já conta com quase 350 mil unidades no Estado. Por isso, ao se priorizar o crescimento destes modos de transporte será necessário prever um programa de controle de NOx específico para locomotivas e embarcações a diesel. 


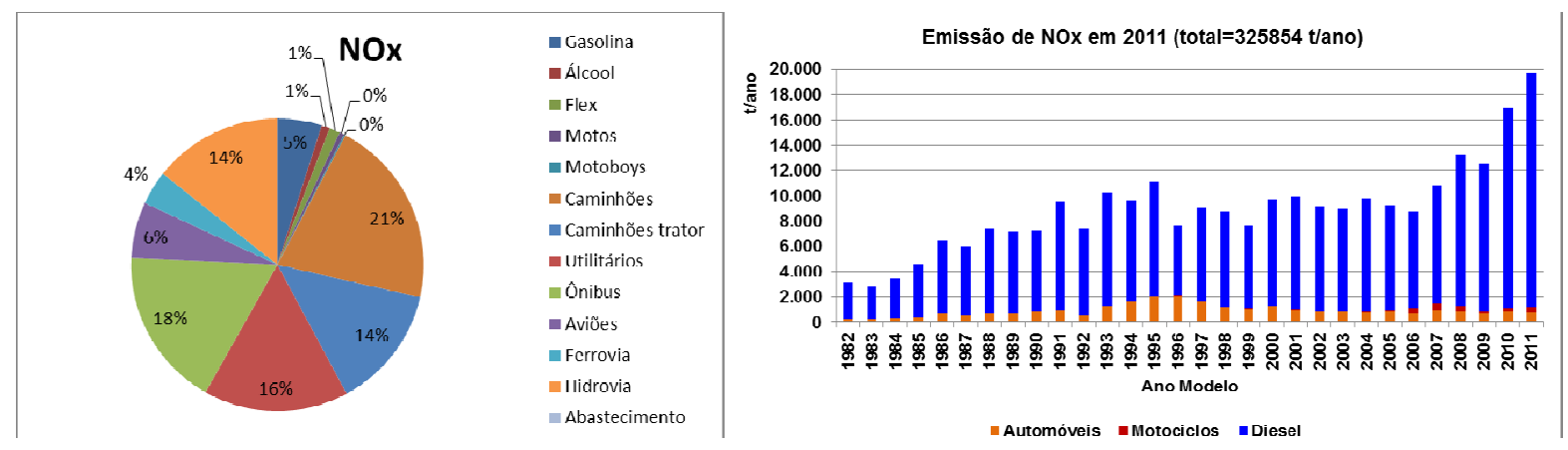

Figura 4.3 - Distribuições da emissão de NOx por categoria de veículo e por ano de fabricação dos veículos rodoviários

\section{d) Compostos orgânicos}

A comparação das emissões de compostos orgânicos voláteis não pode ser realizada pela simples comparação das massas emitidas. Os hidrocarbonetos, aldeídos e etanol atuam principalmente como poluentes secundários, participantes das reações fotoquímicas atmosféricas com o NOx, que resultam na formação de ozônio nas camadas de baixa altitude. Neste processo, cada composto produz efeitos diferentes, segundo a sua reatividade, caracterizada pela MIR, como mencionado em 3.1.

A tabela 4.2 permite esta comparação através dos potenciais de formação de ozônio obtidos pela conversão de cada componente das emissões orgânicas mostradas em massa na tabela anterior, segundo a origem e tipo de veículo. Convertidos em potencial de ozônio, os compostos orgânicos tornam-se comparáveis numa base comum e podem ser somados para melhor avaliação de seus efeitos em termos das suas contribuições relativas.

Para efeito de visualização, a quantidade total de ozônio e as parcelas correspondentes a cada grupo de compostos orgânicos podem ser novamente convertidas para uma massa hipotética de gasolina que produzisse o mesmo efeito, denominada "HC equivalente", de forma a tornar os fatores numéricos comparáveis aos internacionais baseados nos efeitos da gasolina.É importante ressaltar que a simples soma das massas dos diversos compostos determinadas pela leitura dos detetores de ionização de chama (FID) não diferem muito, entretanto ao se comparar emissões de álcool com as de hidrocarbonetos, há diferenças significativas nos seus efeitos em favor do etanol que devem ser consideradas, como considerado nesta análise.

Tabela 4.2 - Potencial de formação de ozônio decorrentes das emissões de VOC por origem e tipo de veículo - ton $\mathrm{O}_{3} /$ ano 


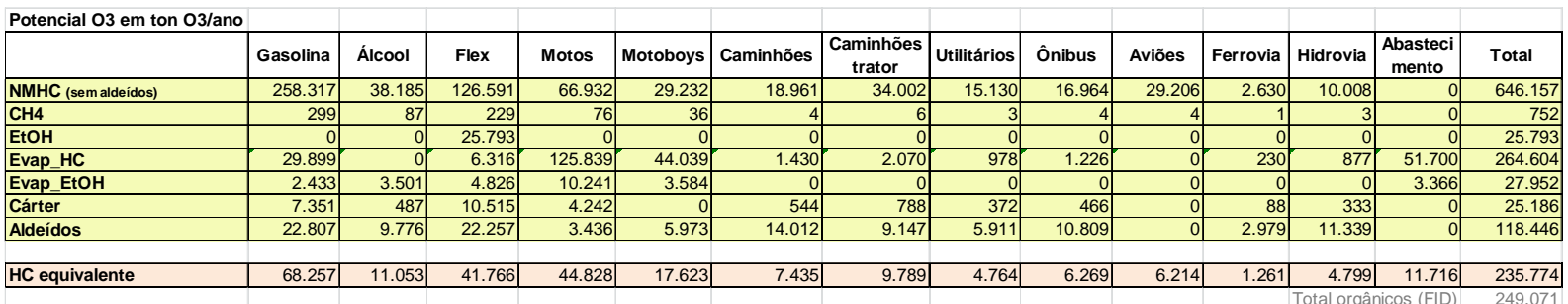

Para uma análise comparativa, todos os resultados comentados acima foram recalculadas em percentagens do $\mathrm{HC}$ equivalente total, tal como apresentados na tabela 4.3., de forma a comparar as diversas fontes de todos os modos de transporte em termos da formação de ozônio ou de HC equivalente.

Tabela 4.3 - Contribuição relativa das emissões de VOC por classe de compostos e tipo de veículo para o potencial de formação de ozônio

\begin{tabular}{|c|c|c|c|c|c|c|c|c|c|c|c|c|c|c|}
\hline & Gasolina & Álcool & Flex & Motos & Motoboys & Caminhões & \begin{tabular}{|c|}
$\begin{array}{c}\text { Caminhões } \\
\text { trator }\end{array}$ \\
\end{tabular} & Utilitários & Ônibus & Aviões & Ferrovia & Hidrovia & \begin{tabular}{|c|}
$\begin{array}{c}\text { Abasteci } \\
\text { mento }\end{array}$ \\
\end{tabular} & Total \\
\hline NMHC (sem aldeídos) & $23,3 \%$ & $3,4 \%$ & $11,4 \%$ & $6,0 \%$ & $2,6 \%$ & $1,7 \%$ & $3,1 \%$ & $1,4 \%$ & $1,5 \%$ & $2,6 \%$ & $0,2 \%$ & $0,9 \%$ & $0,0 \%$ & $58 \%$ \\
\hline CH4 & $0,0 \%$ & $0,0 \%$ & $0,0 \%$ & $0,0 \%$ & $0,0 \%$ & $0,0 \%$ & $0,0 \%$ & $0,0 \%$ & $0,0 \%$ & $0,0 \%$ & $0,0 \%$ & $0,0 \%$ & $0,0 \%$ & $0 \%$ \\
\hline EtOH & $0 \%$ & $0,0 \%$ & $2,3 \%$ & $0,0 \%$ & $0,0 \%$ & $0,0 \%$ & $0,0 \%$ & $0,0 \%$ & $0,0 \%$ & $0,0 \%$ & $0,0 \%$ & $0,0 \%$ & $0,0 \%$ & $2 \%$ \\
\hline Evap_HC & $2,7 \%$ & $0,0 \%$ & $0,6 \%$ & $11,3 \%$ & $4,0 \%$ & $0,1 \%$ & $0,2 \%$ & $0,1 \%$ & $0,1 \%$ & $0,0 \%$ & $0,0 \%$ & $0,1 \%$ & $4,7 \%$ & $24 \%$ \\
\hline Evap_EtOH & $0,2 \%$ & $0,3 \%$ & $0,4 \%$ & $0,9 \%$ & $0,3 \%$ & $0,0 \%$ & $0,0 \%$ & $0,0 \%$ & $0,0 \%$ & $0,0 \%$ & $0,0 \%$ & $0,0 \%$ & $0,3 \%$ & $3 \%$ \\
\hline Cárter & $0,7 \%$ & $0,0 \%$ & $0,9 \%$ & $0,4 \%$ & $0,0 \%$ & $0,0 \%$ & $0,1 \%$ & $0,0 \%$ & $0,0 \%$ & $0,0 \%$ & $0,0 \%$ & $0,0 \%$ & $0,0 \%$ & $2 \%$ \\
\hline Aldeídos & $2,1 \%$ & $0,9 \%$ & $2,0 \%$ & $0,3 \%$ & $0,5 \%$ & $1,3 \%$ & $0,8 \%$ & $0,5 \%$ & $1,0 \%$ & $0,0 \%$ & $0,3 \%$ & $1,0 \%$ & $0,0 \%$ & $11 \%$ \\
\hline HC equivalente & $29 \%$ & $5 \%$ & $18 \%$ & $19 \%$ & $7 \%$ & $3 \%$ & $4 \%$ & $2 \%$ & $3 \%$ & $3 \%$ & $1 \%$ & $2 \%$ & $5 \%$ & $100 \%$ \\
\hline
\end{tabular}

Comparando-se as contribuições totais dos diversos modos de transportes em $\mathrm{HC}$ equivalente, mostradas na última linha da tabela, observa-se que o veículo leve a gasolina ainda é o principal emissor de compostos orgânicos, com $29 \%$ dos $\mathrm{HC}$ equivalentes, sendo $26 \%$ emitidos pelo escapamento.

Em segundo lugar, estão as motos que totalizam $27 \%$, cabendo $16 \%$ à emissão evaporativa ainda não regulamentada. $O$ terceiro emissor mais relevante são os veículos flex com $18 \%$ dos $\mathrm{HC}$ equivalentes, sendo $11,5 \%$ relativos aos hidrocarbonetos de escapamento decorrentes da opção pelo uso de gasolina em metade da frota.

Estas emissões não se concentram em determinados anos de fabricação, mas se distribuem uniformemente nos veículos de até 20 anos, como mostra a figura 4.4 a seguir, que contempla as maiores contribuições. Por esta razão, há um grande potencial de redução destas emissões no Programa de Inspeção e Manutenção que, em 2011 reduziu $39 \%$ e $42 \%$ da emissão de escapamento das frotas Otto e de motos, respectivamente, na cidade de São Paulo. Entretanto, restrições maiores também são recomendáveis para os veículos novos, especialmente para as emissões evaporativas de motos, que podem ser praticamente eliminadas, conforme ocorrido com os automóveis. 


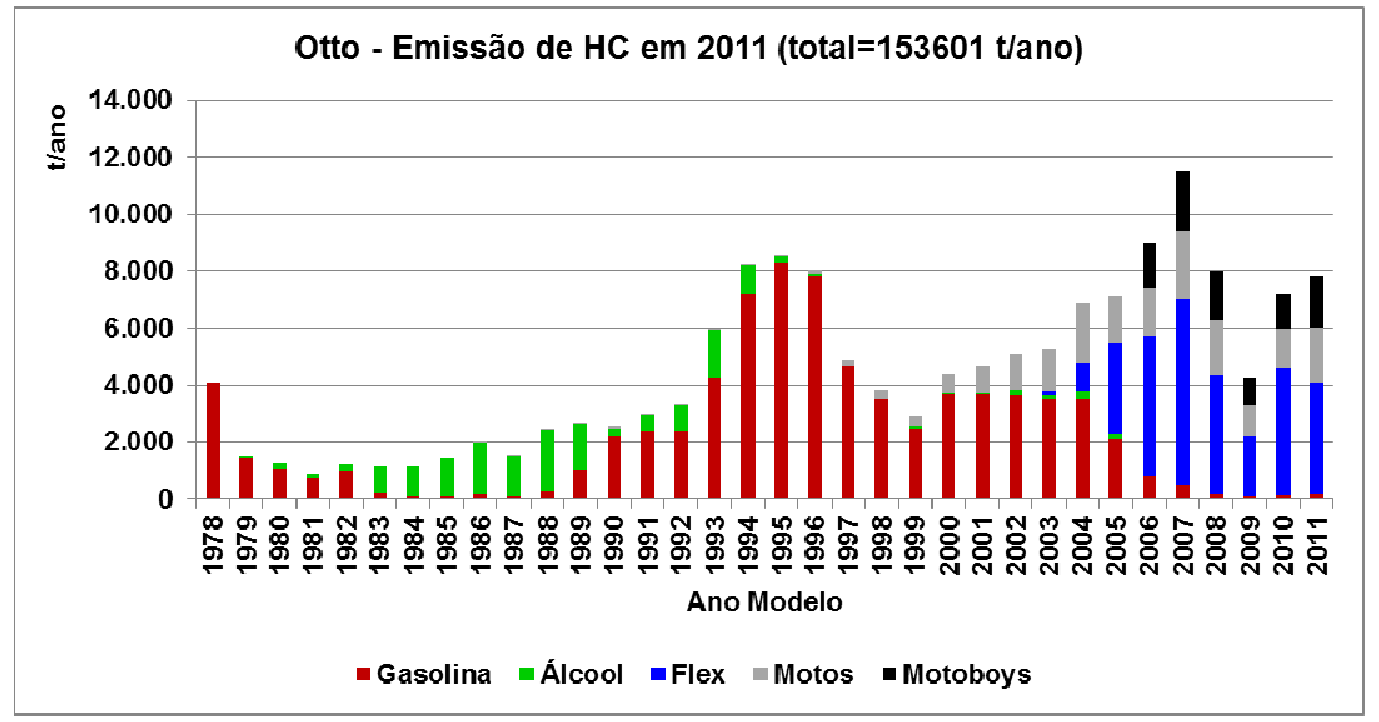

Figura 4.4 - Distribuições da emissão de HC por categoria de veículo e por ano de fabricação dos veículos de transporte individual

Finalmente, identificam-se os veículos Diesel, liderados pelos caminhões, que totalizam $11 \%$ dos $\mathrm{HC}$ equivalentes. É importante destacar a parcela de aldeídos emitida pelos veículos a diesel, que se afigura como $3,4 \%$ dos $\mathrm{HC}$ equivalentes totais, portanto mais expressivas do que a emissão deste poluente pelos veículos a álcool e flex que já são objeto de controle pelo CONAMA. Como os fatores de emissão de aldeídos utilizados foram obtidos de fontes esparsas e de forma imprecisa, é necessário aprimorar o levantamento de dados com valores mais precisos para confirmação deste fato, o que se espera em curto prazo mediante decisão já tomada pelo CONAMA, que determinou a entrega das primeiras medições de valores típicos de aldeídos para motores Diesel, em dezembro de 2012 ao IBAMA.

Considerando que o problema de ozônio é atualmente o aspecto da poluição local do ar mais preocupante atualmente, que as emissões orgânicas constituem-se no fator determinante para a sua formação, e em cada agrupamento de fontes existem contribuições entre $2 \%$ e $4 \%$ que já estão sendo consideradas pelo CONAMA, não se pode deixar de apontar a necessidade de restringir as emissões provenientes do reabastecimento de combustível que totalizam $4 \%$ e podem contribuir com uma redução não desprezível, especialmente por contar com técnicas de alta eficácia que podem eliminá-la quase que totalmente. 


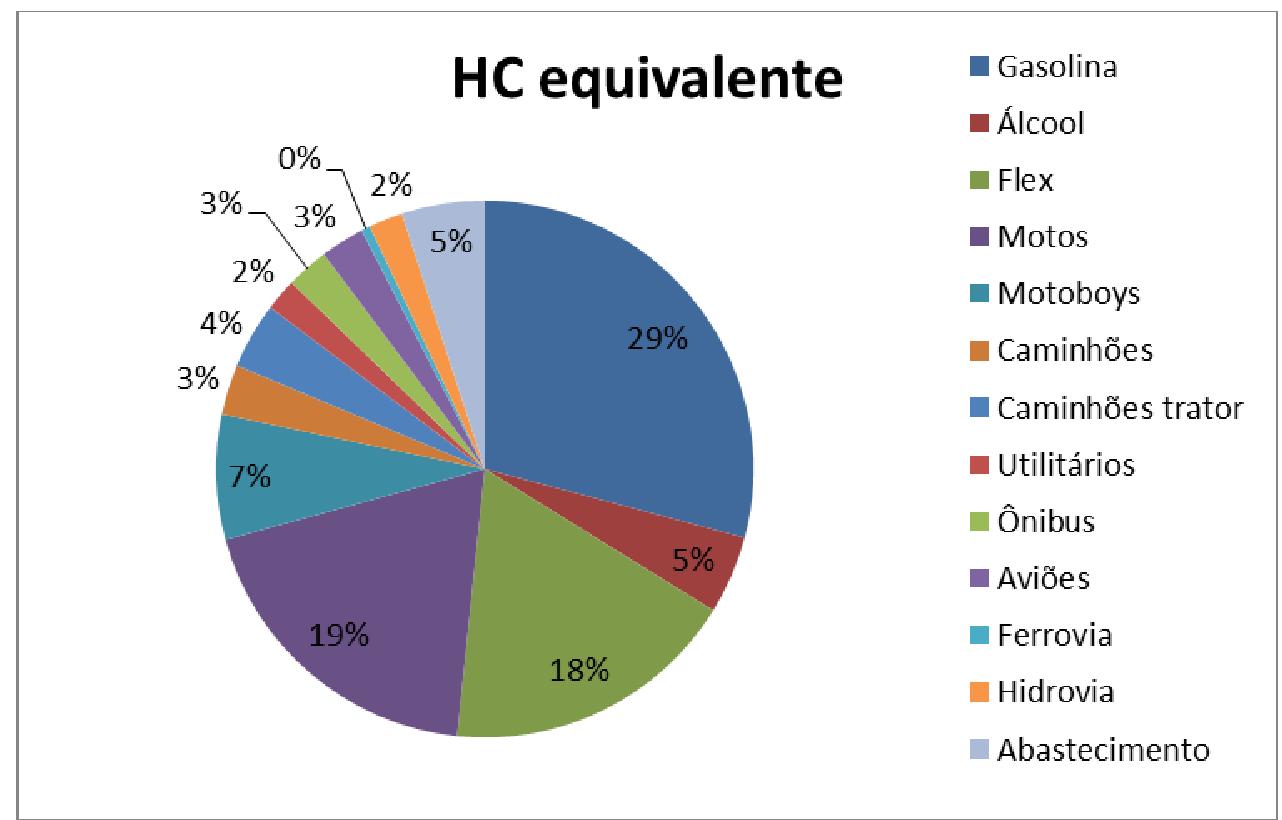

Figura 4.5 - Distribuições da emissão de HC equivalente segundo o potencial de formação de ozônio por categoria de veículo

É importante notar que os veículos rodoviários totalizam 95\% do potencial dos compostos orgânicos para a formação de ozônio de origem veicular, dos quais $84 \%$ são hidrocarbonetos, sendo $5 \%$ devido ao abastecimento.

Os demais modos de transporte ainda não apresentam contribuições significativas de compostos orgânicos, entretanto a sua expansão deve contemplar o controle dessas emissões preventivamente, para evitar que se tornem expressivas nos cenários futuros, especialmente as de hidrocarbonetos e aldeídos.

Também é necessário lembrar que esta análise partiu das fontes mais expressivas, mas as recomendações podem e devem ser estendidas aos veículos que tenham semelhança tecnológica e possam se beneficiar do desenvolvimento dos demais, formando um conjunto relevante. De modo geral, os itens coloridos em rosa na tabela 4.3 representam os alvos principais que devem constar da estratégia de controle da emissão de compostos orgânicos voláteis.

\subsection{Gases de efeito estufa - GEE}

Com relação aos gases de efeito estufa, este inventário demonstra que a quase totalidade das emissões de GEE provenientes dos transportes se concentram no dióxido de carbono, como mostram as tabelas 4.4 e 4.5.

Tabela 4.4 - Emissão de GEE por tipo de veículo - mil ton/ano $\mathrm{CO}_{2}$ equivalente 


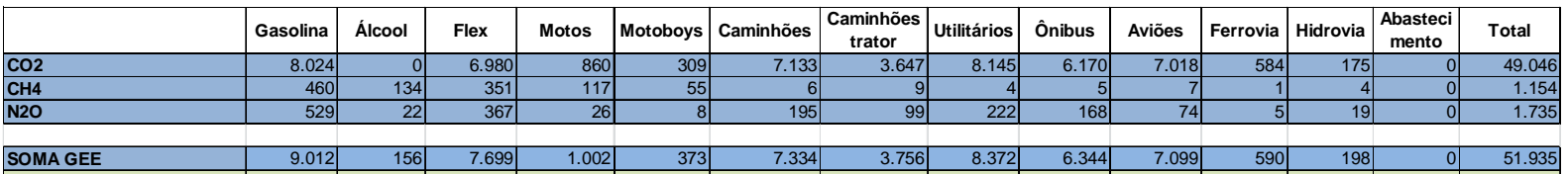

É importante observar que a utilização tradicional de etanol como combustível já representa uma significativa redução da emissão de gases de efeito estufa no setor de transportes, pois se esta estratégia não existisse a emissão de GEE seria atualmente $26 \%$ superior (tomando a atual como base). Nas frotas flex e a álcool esta proporção se elevaria a duas e quatro vezes os valores atuais, como mostra a tabela 4.5.

Este fato ressalta a importância do reconhecimento das estratégias brasileiras já postas em prática e de uma política de conservação e ampliação destas conquistas, como incentivar o uso do etanol nos veículos flex, cujo efeito poderia ser duplicado em relação ao ocorrido em 2011, visto que apenas a metade da frota de São Paulo foi abastecida com álcool, por influência da disparidade de preços entre o álcool e a gasolina sobre a decisão do consumidor.

A figura 4.5 também ilustra a visualização estratégica em função da semelhança entre os diversos setores considerados, segundo o tipo de motor, 0 combustível, a função no transporte e a existência de programas que já exerçam influência nesta questão.

\section{Tabela 4.5 - Contribuição relativa das emissões de GEE por tipo de veículo}

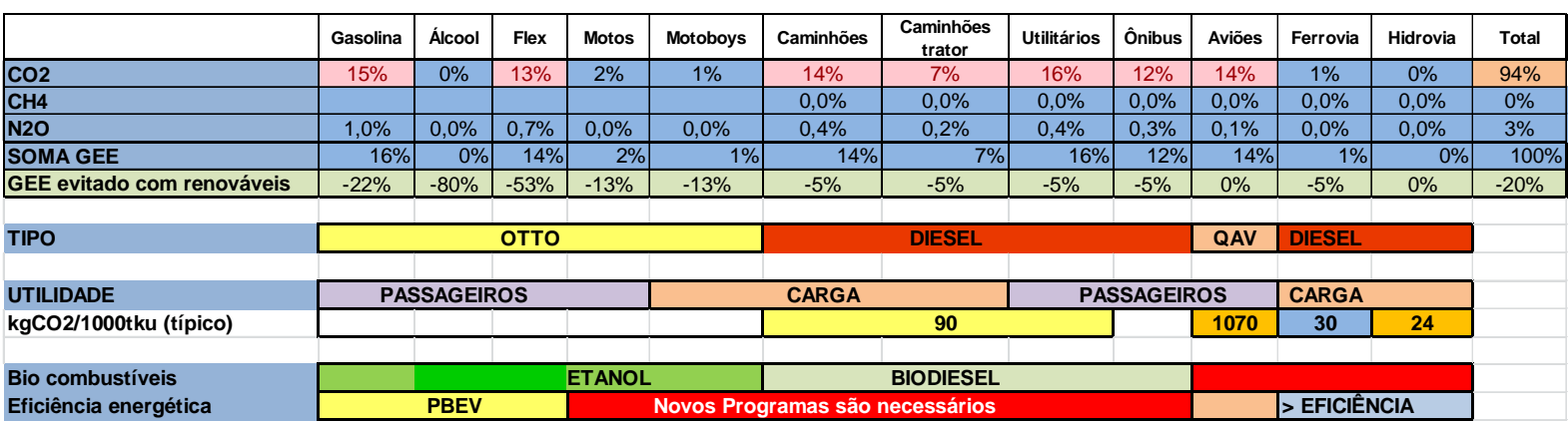

Apesar de os fatores de emissão de $\mathrm{CH}_{4}$ e $\mathrm{N}_{2} \mathrm{O}$ não serem precisos e estarem superestimados, estas emissões são de pequeno significado quando comparadas às de $\mathrm{CO}_{2}$ das mesmas fontes. Por isso, podem ser desprezadas nas estratégias voltadas à redução do efeito estufa causado pelos transportes, não requerendo prioridade no aprimoramento de seus levantamentos.

A figura 4.6 e a tabela 4.5 identificam os veículos a diesel como os maiores produtores de GEE e mostram a necessidade de programas específicos para elevação da eficiência energética e incremento da participação de fontes renováveis nos veículos atualmente movidos a óleo diesel.

Considerando as diferenças de eficiência geral dos modos de transporte, a expansão dos modos ferro e hidroviário poderá ser uma ferramenta relevante para a 
redução do efeito estufa associado aos transportes, pois podem apresentar melhor consumo energético por tonelada-km. Entretanto, a eficiência energética e a emissão de poluentes dos seus propulsores deverá ser objeto de regulamentação rigorosa, atualmente inexistente, em todos os setores de transporte para assegurar os benefícios esperados e a competitividade econômica, como comentado em 3.7. no caso das ferrovias.

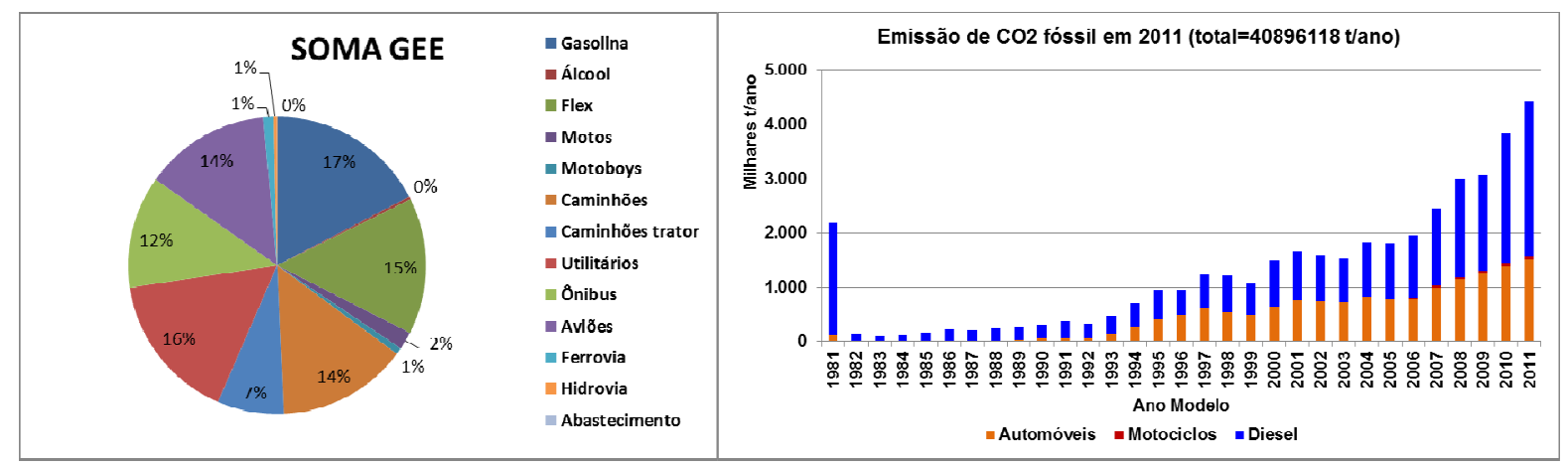

Figura 4.6 - Contribuição relativa das fontes de GEE nos transportes

As contribuições dos veículos leves e aeronaves também apresentam parcelas relevantes que devem ser consideradas. A figura 4.7 indica que a participação mais expressiva dos veículos leves é dos veículos flex que não utilizam etanol (51\% em 2011), o que pode ser resolvido com estratégias que fortaleçam o mercado de álcool e incentivem a utilização deste combustível. Os veículos a gasolina já não possuem grande significado devido ao seu sucateamento natural e a atualmente constituírem pequena parcela do mercado. Entretanto este tipo de veículo e a própria gasolina devem ser considerados nas estratégias para redução de GEE porque, se a sua participação voltar a crescer como indica a tendência dos últimos anos, a sua importância poderá ser até duas vezes mais significativa do que a dos veículos flexque, neste cenário, apresenta somente a parcela fóssil dessa emissão.

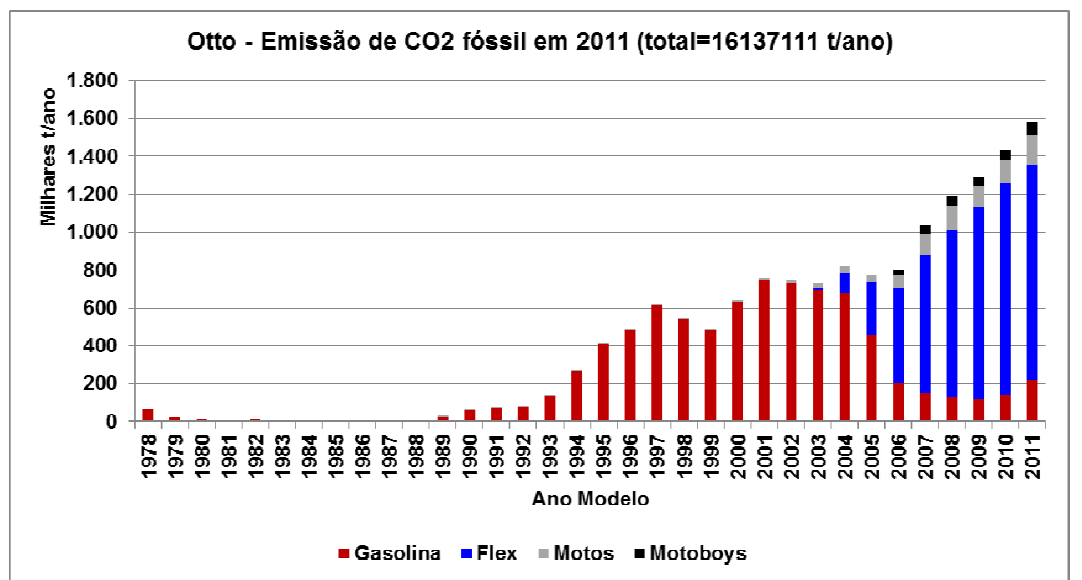

Figura 4.7 - Contribuição do transporte individual na emissão de GEE 
De uma forma geral, todos os tipos de veículos devem ser objeto de programas de melhoria da eficiência energética. Os veículos leves já estão contemplados atualmente pelo PBEV - Programa Brasileiro de Eficiência Energética Veicular, entretanto suas metas devem ser revistas para que tecnologias revolucionárias possam ser viabilizadas no Brasil, como a dos veículos elétricos híbridos, os motores Otto com injeção direta e a aplicação de motores flex associadas a estas duas tecnologias. Para isso, revisões no sistema tributário serão necessárias para aumentar os custos das alternativas que mais comprometem o meio ambiente e diminuí-los nas alternativas tecnológicas melhores, que devem ter o desenvolvimento incentivado.

Por outro lado, a matriz de transportes precisa ser modificada para que os modos mais eficientes e de baixa emissão sejam priorizados em favor da redução do uso de automóveis e caminhões, sempre que possível. É neste sentido que o PDLT 2030 deve ser orientado.

\section{Conclusões}

Os estudos mencionados neste trabalho são os únicos disponíveis até o momento para a determinação de fatores de deterioração real da frota em circulação. Por isso,os fatores apresentados deverão ser revistos e aprimorados durante o desenvolvimento do PDLT 2030, com base nos fatores médios emissão detectados pelo programa I/M-SP para os veículos reprovados, assumidos como não conformes, e para os veículos aprovados (veículos com degradação normal).A determinação de fatores reais de deterioração deve ser incentivada, inclusive para os veículos não rodoviários que ainda não tiveram estes índices estimados.

O conhecimento das emissões evaporativas e de aldeídos deve ser aprofundado para permitir estimativas mais precisas que possam nortear as estratégias para a mitigação do ozônio. Neste sentido, será necessário um inventário de fontes fixas das fontes de VOC em todo o Estado.

Os dados disponíveis sobre as ferrovias revelam a necessidade de comprovação dos mesmos e da regulamentação de programas de eficiência energética e emissões deste setor, simultaneamente com os incentivos para o seu crescimento. O mesmo se aplica ao setor hidroviário.

As estratégias de mitigação do ozônio de baixa altitude devem contemplar todos os setores de transporte, principalmente os veículos rodoviários, inclusive as operações de abastecimento e transferência de combustíveis. São alvos principais as emissões de hidrocarbonetos (todos os veículos e os abastecimentos), aldeídos (diesel) e etanol (flex).

De maneira geral, a tabela 5.1 indica os segmentos que devem ser contemplados por programas de redução de emissões, sejam intensificando os programas existentes (I), ou mediante o desenvolvimento de regulamentações novas (R) ou ainda indicando a necessidade de levantamento de dados ( $L$ ) para o aprimoramento do conhecimento atual. 
Tabela 5.1 - Visão geral da necessidade de estratégias ambientais associadas ao PDLT2030

\begin{tabular}{|c|c|c|c|c|c|c|c|c|}
\hline & $\begin{array}{l}\text { Leves } \\
\text { Otto }\end{array}$ & Motos & $\begin{array}{l}\text { Abaste- } \\
\text { cimento }\end{array}$ & $\begin{array}{l}\text { Leves } \\
\text { diesel }\end{array}$ & \begin{tabular}{|c|} 
Diesel \\
Pesados
\end{tabular} & Aviões & Ferrovia & Hidrovia \\
\hline NMHC & I & I & & & & $\mathbf{R}$ & $\mathbf{R}$ & $\mathbf{R}$ \\
\hline $\mathrm{EtOH}$ & $R$ & R & & & & & & \\
\hline Evap_HC & & $\mathbf{R}$ & $\mathbf{R}$ & & & & & \\
\hline Evap_EtOH & & $\mathbf{R}$ & $\mathbf{R}$ & & & & & \\
\hline Cárter & & & & & & & & \\
\hline Aldeídos & & L/R & & $\mathbf{R}$ & $\mathbf{R}$ & $\mathbf{L}$ & $\mathbf{R}$ & $\mathbf{R}$ \\
\hline NMHCtotal & & & & & & & & \\
\hline EtOH_total & & & & & & & & \\
\hline $\mathrm{CO}$ & I & I & & & & & & \\
\hline NOx & & & & & & & $\mathbf{R}$ & $\mathbf{R}$ \\
\hline MP & $\mathbf{R}$ & & & I & I & $\mathbf{L}$ & $\mathbf{R}$ & $\mathbf{R}$ \\
\hline $\mathrm{CO}_{2}$ fóssil & I & $\mathbf{R}$ & & $\mathbf{R}$ & $\mathbf{R}$ & $R$ & $\mathbf{R}$ & $\mathbf{R}$ \\
\hline $\mathrm{CO}_{2}$ renovável & I & I & & I & I & $\mathbf{R}$ & & \\
\hline $\mathrm{CH}_{4}$ & \multirow{3}{*}{\multicolumn{8}{|c|}{ não significativos para a emissão de GEE }} \\
\hline $\mathrm{N}_{2} \mathrm{O}$ & & & & & & & & \\
\hline $\mathrm{NH}_{3}$ & & & & & & & & \\
\hline
\end{tabular}

Legenda: $\mathbf{I}=$ intensificar programa; $\quad \mathbf{R}=$ regulamentar; $\mathbf{L}=$ levantar dados

Apesar das incertezas sobre os dados reais dos segmentos ferroviário e hidroviário, é importante ressaltar que além de uma revisão da eficácia desses sistemas de transporte, a sua expansão implicará também na sua evolução tecnológica para a aplicação de motores de baixa emissão de poluentes, justificando um Programa Ambiental Preventivo para locomotivas e embarcações nos mesmos moldes dos que o CONAMA já definiu para veículos leves, motos, caminhões, ônibus e máquinas rodoviárias, bem como na sua melhoria em termos de eficiência energética.

Com relação à mitigação das emissões de GEE, deve-se ressaltar a importância da recuperação do interesse pelo uso do álcool em veículos flex, pois esta é a estratégia mais efetiva atualmente para o uso de combustíveis renováveis, que poderá se perder, novamente por falha estratégica de continuidade dessa medida, cujos interesses ambientais estão diretamente voltados às reduções de GEE e ozônio troposférico. Nos setores hidroviário e ferroviário, deve-se pensar em alternativas energéticas de menor impacto sobre os GEE, como o uso de biocombustíveis e eletrificação das ferrovias entre outros. 


\section{Bibliografia}

${ }^{1}$ CONTROLAR/SVMA - Levantamento da Quilometragem média anual dos veículos inspecionados em 2011.

2 Branco, G.M.; Szwarc, A.; Branco, F.C. - POLUIÇÃO DO AR POR VEÍCULOS: Fundamentos, Tecnologias de Controle, Combustíveis e Medições - curso ministrado pela última vez em 2012

${ }^{3}$ Anuário Estatístico de Energéticos por Municípios no Estado de São Paulo - 2010

4 IPCC- Good Practice Guidance and Uncertainty Management in National Greenhouse Gas Inventories

${ }^{5}$ Scatolini, F. - MCT-Ministério da Ciência e Tecnologia/Instituto de Aviação Civil - IAC - Primeiro Inventário Brasileiro de Emissões Antrópicas de Gases de Efeito Estufa - 2006

${ }^{6}$ Carter, W.P.L.- Updated Maximum Incremental Reactivity Scale and Hydrocarbon Bin Reactivities for Regulatory Applications - Prepared for California Air Resources Board - Revised January 28, 2010

7 Branco, G.M.; Szwarc, A.; Branco, F.C.; Nigro, F.E.B. - Controle de Emissão de Compostos Orgânicos com base no Potencial de Formação de Ozônio - proposto para o XXI SIMEA - 2013

${ }^{8}$ http://www.anp.gov.br/?pg=59236\&m=\&t1=\&t2=\&t3=\&t4=\&ar=\&ps=\&cachebust=1355404267187

${ }^{9}$ ANFAVEA - Anuário Estatístico da Indústria Automobilística Brasileira - 2012 e anteriores.

${ }^{10}$ Huai, T.; Durbin, T.D.; Miller, J.W.; Norbeck, J.M. - Estimates of the emission rates of nitrous oxide from light-duty vehicles using different chassis dynamometer test cycles - Department of Chemical and Environmental Engineering, Bourns College of Engineering, Center for Environmental Research and Technology, University of California, Riverside, CA 92521, USA. Atmospheric Environment 38 (2004) 6621-6629.

${ }^{11}$ Using MOVES for Estimating State and Local Inventories of On-Road Greenhouse Gas Emissions and Energy Consumption - EPA-420-D-12-001, January 2012

12 Branco, G.M. e Branco, F.C. - INVENTÁRIO DE FONTES MÓVEIS: análise prospectiva e retrospectiva dos benefícios do PROCONVE para a qualidade do ar desde 1980 a 2030. Trabalho elaborado para o Ministério do Meio Ambiente em 2007.

${ }^{13}$ Branco, F.C.; Branco, G.M.; Szwarc,A.; Beccardi, R.B. e Rosin, E.Correlação de Resultados de Inspeção em Marcha Lenta e Medições por Sensoriamento Remoto - menção honrosa no XX SIMEA 2012.

${ }^{14}$ EPA - Health assessment document for diesel engine exhaust, EPA, 2002

${ }^{15}$ Abrantes, R.; Assunção, J.V.; Hirai, E.Y. - Caracterização das emissões de aldeídos de veículos do ciclo Diesel. Revista de Saúdepública, V. 39, N 3, 2005

${ }^{16}$ EPA - Exhaust and Crankcase Emission Factors for Nonroad Engine Modeling - CompressionIgnition - EPA 2010.

${ }^{17}$ EPA - Emission Factors for Locomotives - EPA-420-F-09-025 - April 2009

${ }^{18}$ EPA - Documentation for Locomotive Component of the National Emissions Inventory Methodology - ERG No.: 0245.03.402.001-May 3, 2011

${ }^{19} \mathrm{http}: / /$ www.epa.gov/otaq/ap42.htm - EPA - AP-42 - Compilation of Air Pollutant Emission Factors, 2006

${ }^{20}$ EPA - Health Assessment Document for Diesel Engine Exhaust - EPA/600/8-90/057F - May 2002

${ }^{21}$ EPA - Procedures for Emission Inventory Preparation - Volume IV: Mobile Sources - EPA420-R-92009 - December 1992 
${ }^{22}$ Nigro, F.E.B. - Emissões de HC na RMSP - Significância do Etanol - Grupo de Trabalho AEA Álcool não Queimado - São Paulo, 28/junho/2012 